\title{
\begin{tabular}{l|l} 
Mibraries & DSpace@MIT
\end{tabular}
}

\author{
MIT Open Access Articles
}

\section{6\%-efficient monolithic perovskite/silicon tandem solar cells with improved stability}

The MIT Faculty has made this article openly available. Please share how this access benefits you. Your story matters.

Citation: Bush, Kevin A. et al. “23.6\%-Efficient Monolithic Perovskite/silicon Tandem Solar Cells with Improved Stability." Nature Energy 2, 4 (February 2017): 17009 (C) 2017 Macmillan Publishers Limited, part of Springer Nature

As Published: http://dx.doi.org/10.1038/NENERGY.2017.9

Publisher: Nature Publishing Group

Persistent URL: http://hdl.handle.net/1721.1/118870

Version: Final published version: final published article, as it appeared in a journal, conference proceedings, or other formally published context

Terms of Use: Article is made available in accordance with the publisher's policy and may be subject to US copyright law. Please refer to the publisher's site for terms of use. 


\section{6\%-Efficient Monolithic Perovskite/Silicon Tandem Solar Cells with Improved}

\section{Stability}

Kevin A. Bush ${ }^{\dagger 1}$, Axel F. Palmstrom ${ }^{\dagger 1}$, Zhengshan J. Yu ${ }^{\dagger 2}$, Mathieu Boccard ${ }^{2}$, Rongrong Cheacharoen ${ }^{1}$, Jonathan P. Mailoa ${ }^{3}$, David P. McMeekin ${ }^{4}$, Robert L. Z. Hoye ${ }^{3}$, Colin D. Bailie ${ }^{1}$, Tomas Leijtens ${ }^{1}$, Ian Marius Peters ${ }^{3}$, Maxmillian C. Minichetti ${ }^{1}$, Nicholas Rolston ${ }^{1}$, Rohit Prasanna ${ }^{1}$, Sarah Sofia ${ }^{3}$, Duncan Harwood ${ }^{5}$, Wen $\mathrm{Ma}^{6}$, Farhad Moghadam ${ }^{6}$, Henry J. Snaith ${ }^{4}$, Tonio Buonassisi ${ }^{3}$, Zachary C. Holman*2, Stacey F. Bent ${ }^{1}$, and Michael D. McGehee*1

${ }^{1}$ Stanford University, Stanford, 94305, USA.

${ }^{2}$ Arizona State University, Tempe, 85281, USA.

${ }^{3}$ Massachusetts Institute of Technology, Cambridge, 02139, USA.

${ }^{4}$ University of Oxford, Oxford, UK.

${ }^{5}$ D2 Solar LLC, San Jose, 95131, USA.

${ }^{6}$ SunPreme, Sunnyvale, 94085, USA.

${ }^{\dagger}$ Authors contributed equally to this work

*Mmcgehee@stanford.edu, Zachary.holman@asu.edu

\section{Abstract}

As the record single-junction efficiencies of perovskite solar cells now rival those of CIGS, CdTe, and multicrystalline silicon, they are becoming increasingly attractive for use in tandem solar cells, due to their wide, tunable bandgap and solution processability. Previously, perovskite/silicon tandems were limited by significant parasitic absorption and poor environmental stability. Here, we improve the efficiency of monolithic, two-terminal, $1 \mathrm{~cm}^{2}$ perovskite/silicon tandems to $23.6 \%$ by combining an infrared-tuned silicon heterojunction bottom cell with the recently developed cesium formamidinium lead halide perovskite. This more stable perovskite tolerates deposition of a tin oxide buffer layer via atomic layer deposition that prevents shunts, has negligible parasitic absorption, and allows for the sputter deposition of a transparent top electrode. Furthermore, the window layer doubles as a diffusion barrier, increasing the thermal and environmental stability to enable perovskite devices that withstand a 1000 -hour damp heat test at $85{ }^{\circ} \mathrm{C}$ and $85 \%$ relative humidity.

\section{Introduction}

The rapid rise of perovskite solar cells with record single-junction efficiencies of over $22 \%{ }^{1}$ is the result of a unique combination of properties, including strong optical absorption ${ }^{2}$, long diffusion lengths ${ }^{3}$, and solution processability enabled by the relatively benign nature of intrinsic defects ${ }^{4}$. Additionally, their 
wide, tunable bandgap ${ }^{5}$ makes perovskites highly attractive for use in multijunction solar cells on top of narrower-bandgap absorbers, such as silicon, CIGS, and Sn-containing perovskites ${ }^{6-18}$. This presents a pathway to achieving industry goals of improving efficiencies to over $30 \%{ }^{19}$ while maintaining low module $\operatorname{cost}^{20}$.

The first monolithic perovskite/silicon tandem was made with a diffused silicon $p$ - $n$ junction, a tunnel junction made of $\mathrm{n}^{++}$hydrogenated amorphous silicon, a titania electron transport layer, a methylammonium lead iodide absorber, and a Spiro-OMeTAD hole transport layer (HTL) ${ }^{8}$. The power conversion efficiency (PCE) was only $13.7 \%$ due to excessive parasitic absorption of light in the $H T L$, limiting the matched current density to $11.5 \mathrm{~mA} / \mathrm{cm}^{2}$. Werner et al. ${ }^{15}$ raised the PCE to a record $21.2 \%$ by switching to a silicon heterojunction bottom cell and carefully tuning layer thicknesses to achieve lower optical loss and a higher current density of $15.9 \mathrm{~mA} / \mathrm{cm}^{2}$. It is clear from these reports that minimizing parasitic absorption in the window layers is crucial to achieving higher current densities and efficiencies in monolithic tandems. To this end, the window layers through which light first passes before entering the perovskite and silicon absorber materials must be highly transparent. The front electrode must also be conductive to carry current laterally across the top of the device. Indium tin oxide (ITO) is widely utilized as a transparent electrode in optoelectronic devices such as flat-panel displays, smart windows, organic light-emitting diodes, and solar cells due to its high conductivity and broadband transparency ${ }^{21}$. ITO is typically deposited through magnetron sputtering; however, the high kinetic energy of sputtered particles can damage underlying layers ${ }^{22}$. In perovskite solar cells, a sputter buffer layer is required to protect the perovskite and organic carrier extraction layers from damage during sputter deposition. The ideal buffer layer should also be energetically well aligned so as to act as a carrier-selective contact, have a wide bandgap to enable high optical transmission, and have no reaction with the halides in the perovskite. Additionally, this buffer layer should act as a diffusion barrier layer to prevent both organic cation evolution and moisture penetration to overcome the often-reported thermal and environmental instability of metal halide perovskites ${ }^{23}$. Previous perovskite-containing tandems utilized molybdenum oxide $\left(\mathrm{MoO}_{x}\right)$ as a sputter buffer layer ${ }^{9,11,12}$, but this has raised concerns over long-term stability, as the iodide in the perovskite can chemically react with $\mathrm{MoO}_{x}{ }^{24}$.

Mixed-cation perovskite solar cells have consistently outperformed their single-cation counterparts. The first perovskite device to exceed $20 \%$ PCE was fabricated with a mixture of methylammonium (MA) and formamidinium (FA) ${ }^{25}$. Recent reports have shown promising results with the introduction of cesium mixtures, enabling high efficiencies with improved photo-, moisture, and thermal stability ${ }^{26-30}$. The increased moisture and thermal stability are especially important as they broaden the parameter space for processing on top of the perovskite, enabling the deposition of metal oxide contacts through atomic layer deposition ${ }^{31,32}$ (ALD) or chemical vapor deposition (CVD) that may require elevated temperatures or water as a counter reagent. Both titanium dioxide $\left(\mathrm{TiO}_{2}\right)$ and tin oxide $\left(\mathrm{SnO}_{2}\right)$ have consistently proven to be effective electron-selective contacts for perovskite solar cells and both can be deposited via ALD at temperatures below $150{ }^{\circ} \mathrm{C}^{33-35}$.

Here, we introduce a bilayer of $\mathrm{SnO}_{2}$ and zinc tin oxide (ZTO) that can be deposited by either lowtemperature ALD or pulsed-CVD as a window layer with minimal parasitic absorption, efficient electron 
extraction, and sufficient buffer properties to prevent the organic and perovskite layers from damage during the subsequent sputter deposition of a transparent ITO electrode. We explored pulsed-CVD as a modified ALD process with a continual, rather than purely step-wise, growth component in order to considerably reduce the process time of the $\mathrm{SnO}_{2}$ deposition process and minimize potential perovskite degradation. These layers, when used in an excellent mixed-cation perovskite solar cell atop a silicon solar cell tuned to the infrared spectrum, enable highly efficient perovskite-silicon tandem solar cells with enhanced thermal and environmental stability.

\section{Single-Junction Perovskite Solar Cells}

We first fabricated single-junction perovskite solar cells on ITO-coated glass in order to develop a transferrable architecture for monolithic tandem solar cells on silicon. We fabricated the $\mathrm{Cs}_{0.17} \mathrm{FA}_{0.83} \mathrm{~Pb}\left(\mathrm{Br}_{0.17} \mathrm{l}_{0.83}\right)_{3}$ (CsFA) perovskite top cell, with a bandgap of $1.63 \mathrm{eV}$ (Supplementary Figure 1), in the $p-i-n$ architecture, in which the electron-selective contact is deposited on top of the perovskite absorber layer and acts as a window layer. Suitable contacts for this geometry include $n$-type metal oxides such as zinc oxide $(\mathrm{ZnO}), \mathrm{TiO}_{2}$, and $\mathrm{SnO}_{2}$. Figure 1 a displays a schematic of the device structure. The perovskite was deposited on top of nickel oxide $\left(\mathrm{NiO}_{x}\right)-$ a hole-selective contact-to achieve higher voltage and stability than with the traditional poly(3,4-ethlenedioxythiophene) polystyrene sulfonate (PEDOT:PSS) contact ${ }^{36,37}$. The CsFA perovskite was deposited from a stoichiometric solution containing $\mathrm{Csl}$, formamidinium iodide ( $\mathrm{FAl}$ ), $\mathrm{Pbl}_{2}$, and $\mathrm{PbBr}_{2}$ in a mixture of dimethylformamide (DMF) and dimethyl sulfoxide (DMSO). This deposition method was modified from that of Chenyi et al. ${ }^{27}$ and the full details of device fabrication are provided in the Methods section.

To deposit an electron-selective contact, we attempted to use phenyl-C61-butyric acid methyl ester (PCBM) and aluminum-doped zinc oxide (AZO) nanoparticles, which were previously used successfully in a methylammonium lead iodide $\left(\mathrm{MAPbl}_{3}\right)$ perovskite solar cell ${ }^{38}$; however, the devices were largely shunted due to the high surface roughness of the CsFA perovskite (Supplementary Figure 2). Spin coating on rough surfaces requires thick, planarizing layers to be applied to prevent shunt pathways, leading to lower optical transmission (Supplementary Figure 2). Evaporation, ALD, and CVD enable the fabrication of uniform, conformal, thin films offering high optical transmission, regardless of surface texture. $\mathrm{SnO}_{2}$ can be deposited by ALD using tetrakis(dimethylamino)tin(IV) (TDMASn) and water at temperatures as low as $30{ }^{\circ} \mathrm{C}^{39}$, although deposition temperature is known to affect the stoichiometry and electronic properties of metal oxide films ${ }^{40}$. We use this ALD system at $100{ }^{\circ} \mathrm{C}$ to deposit $\mathrm{SnO}_{2}$. Others have shown that a thin layer of PCBM between $\mathrm{SnO}_{2}$ and the perovskite increases efficiency ${ }^{29}$. We thermally evaporated $1 \mathrm{~nm}$ of $\mathrm{LiF}$ and $10 \mathrm{~nm}$ of PCBM to leverage their good electron extraction properties (Supplementary Figure 3), while still achieving high optical transmission. We find that LiF acts as a shunt blocking layer similar to how thin, insulating, silicon oxide layers have been employed previously in thin-film silicon solar cells to block shunt pathways and increase fill factor $(F F)^{41}$. We believe LiF helps enable us to fabricate our $1 \mathrm{~cm}^{2}$ aperture area tandems without a loss in $F F$ and a large spread in efficiency (see Supplementary Figure 9). 
Additionally, we note that PCBM thermally decomposes during evaporation to a more thermally stable isomer with very similar electronic properties ${ }^{42}$.

On top of the PCBM layer, we deposited $4 \mathrm{~nm}$ of $\mathrm{SnO}_{2}$ by ALD at $100{ }^{\circ} \mathrm{C}$, followed by $2 \mathrm{~nm}$ of ZTO. The $X$-ray photoelectron spectroscopy (XPS) sputter depth profile of the $4 \mathrm{~nm} \mathrm{SnO} / 2 \mathrm{~nm}$ ZTO stack in Supplementary Figure 4 shows only partial diffusion of zinc into the tin oxide film, indicating that $4 \mathrm{~nm}$ of $\mathrm{SnO}_{2}$ is sufficient to prevent detectable concentrations of zinc from reaching the perovskite. ZTO was deposited by combining $\mathrm{SnO}_{2}$ and $\mathrm{ZnO}$ ALD processes in a repeating supercycle consisting of three cycles of $\mathrm{SnO}_{2}$ followed by three cycles of $\mathrm{ZnO}^{43,44}$. The parameters for the individual $\mathrm{SnO}_{2}$ and $\mathrm{ZnO}$ processes used in the ZTO supercycle are described in Supplementary Tables 1-4. This process resulted in an effective growth rate of $5.8 \AA$ /supercycle, or $0.1 \mathrm{~nm} / \mathrm{min}$. We investigated faster processing methods of our window layer by reducing the purge time from $30 \mathrm{sec}$ to $5 \mathrm{sec}$ between pulses. In doing so, the process approached the pulsed-CVD growth regime, further increasing the deposition rate to $0.5 \mathrm{~nm} / \mathrm{min}$, resulting in a total window layer deposition time of approximately $15 \mathrm{~min}$. Current-voltage $(J-V)$ and XPS data in Supplementary Figures 5 and 6 illustrate the identical performance and stoichiometry of $\mathrm{SnO}_{2}$ and ZTO layers deposited via ALD and pulsed-CVD. Pulsed-CVD was used in the fabrication of our champion devices, which is noteworthy as CVD has the potential to reduce processing time compared to ALD and minimize thermal-induced degradation during processing.

A 150-nm-thick ITO electrode with a sheet resistance of $30 \Omega / \square$ was sputtered on top of the cell, as in our previous work ${ }^{38}$. Optical modelling of the device stack indicated that thicker ITO layers introduce significant current losses through parasitic absorption (Supplementary Figure 7) while thinner layers reduce $F F$ due to high series resistance. The $2 \mathrm{~nm}$ of ZTO is necessary to achieve low contact resistance with ITO and reach a high FF, as shown in Supplementary Figure 3. Finally, we finished the device stack with an evaporated silver metal electrode around the perimeter of the $1 \mathrm{~cm}^{2}$ device area to minimize series resistance and a 150-nm-thick, thermally evaporated LiF antireflection coating.
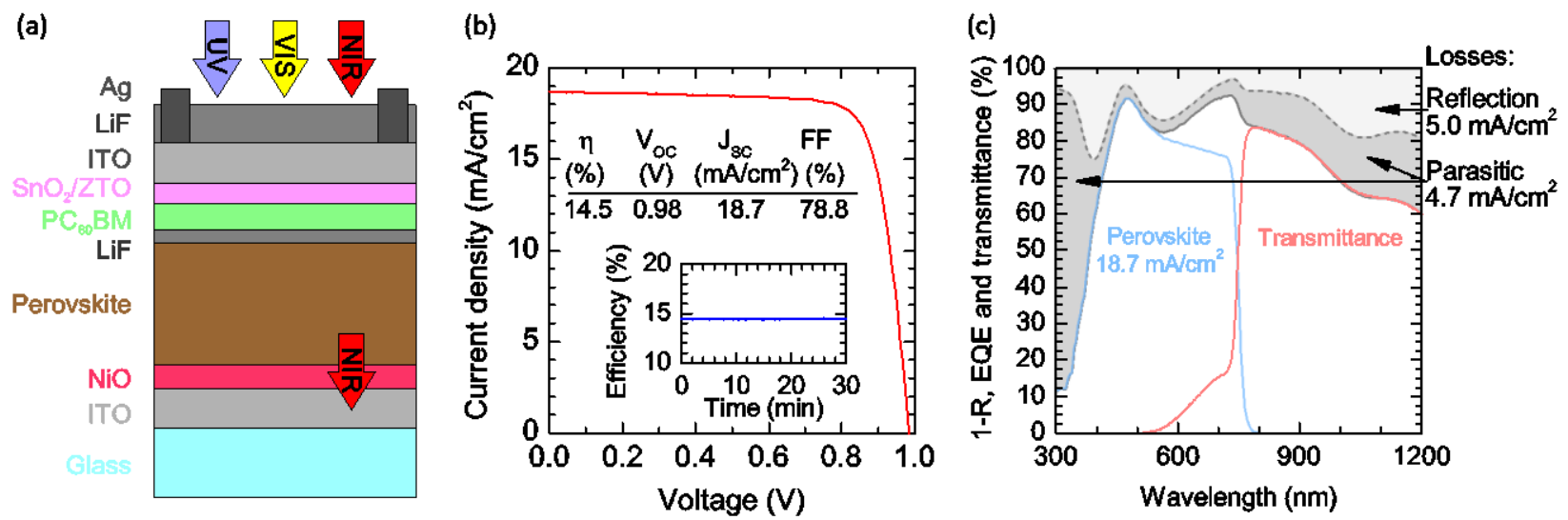

Figure 1. Design and performance of the perovskite top cell. (a) Schematic of the single-junction, semitransparent perovskite solar cell (not to scale), (b) J-V curve and efficiency at the maximum power point (inset) of the perovskite solar cell with illumination through the $\mathrm{SnO}_{2}$ side, (c) total absorbance (1-R, where $R$ is the reflectance; dashed grey line), EQE (solid blue line), and transmittance (solid red line) of 
the perovskite solar cell. The sum of the EQE and transmittance (solid grey line) is the total summed current density available to be captured in the final tandem. The light and dark grey shaded areas represent the light lost to reflection and parasitic absorption, respectively, and the associated current density losses are indicated.

Supplementary Figure 3 displays the $J-V$ curves of a semi-transparent device on glass compared to a reference opaque device, in which an aluminum electrode was evaporated onto the $\mathrm{SnO}_{2} / \mathrm{ZTO}$ bilayer instead of sputtering an ITO electrode. The equivalent efficiency of the semi-transparent and opaque devices speaks to the efficacy of the $\mathrm{SnO}_{2} /$ ZTO bilayer and sputtered ITO layer as an electron-selective contact. Additionally, the high $F F$ of $78.8 \%$ and lack of an extraction barrier, demonstrated by the $J-V$ curve in Figure $1 b$, indicate that the bilayer is a successful sputter buffer layer. Figure $1 c$ shows the external quantum efficiency (EQE), transmittance, and 1-reflectance measured from the $\mathrm{SnO}_{2} / \mathrm{ZTO}$ bilayer (front) side. The high EQE, with an integrated current density of $18.7 \mathrm{~mA} / \mathrm{cm}^{2}$, and low parasitic losses between 400 and $750 \mathrm{~nm}$ showcase the optical properties of the bilayer and sputtered ITO. The AM1.5G-weighted average transmittance of this device between the perovskite bandgap at $765 \mathrm{~nm}$ and the silicon bandgap at $1200 \mathrm{~nm}$ is $74 \%$. Figure $1 \mathrm{~b}$ indicates that there is still room for open-circuit voltage $\left(V_{o c}\right)$ improvement, as the bandgap-voltage offset is over $0.65 \mathrm{~V}$. We believe that the origin of the voltage loss is primarily due to the difficultly in crystallizing the CsFA perovskite in the inverted architecture on a planar surface. Supplementary Figure 2 reveals considerable surface roughness, which may cause voids in the LiF and PCBM layers during the evaporation.

Two-Terminal Tandem Solar Cells 

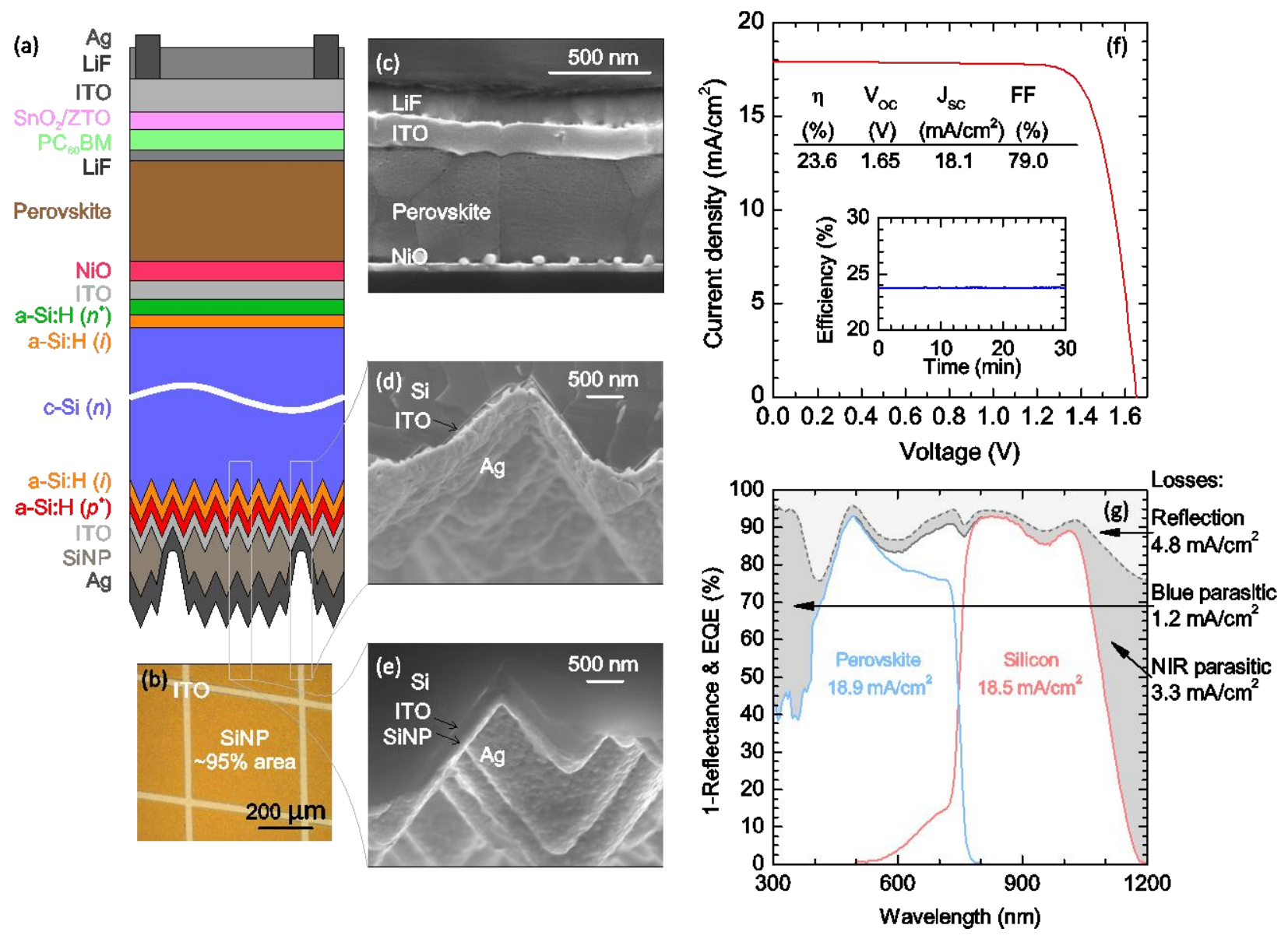

Figure 2. Design and performance of the perovskite/silicon tandem cell. (a) Schematic of the perovskite/silicon tandem solar cell (not to scale), (b) optical microscope image of the siliconnanoparticle-patterned rear side of the silicon cell before silvering, (c) cross-sectional SEM image of the perovskite top cell, (d) cross-sectional SEM image of the rear side of the silicon cell in an area with no silicon nanoparticles, (e) cross-sectional SEM image of the rear side of the silicon cell in an area with silicon nanoparticles, (f) J-V curve (NREL certified, see Supplementary Figure 8) and efficiency at the maximum power point (inset) of the champion tandem device, $(g)$ total absorbance (1-R, where $R$ is the reflectance; dashed grey line), EQE of the perovskite top cell (solid blue line), and EQE of the silicon bottom cell (solid red line). The sum of the EQEs is denoted by the solid grey line. The light and dark grey shaded areas represent the light lost to reflection and parasitic absorption, respectively, and the associated current density losses are indicated.

To form two-terminal perovskite/silicon tandem solar cells, perovskite cells were fabricated directly on top of complete silicon bottom cells, as shown in Figure 2a. The perovskite top cells, one of which is shown in cross section in Figure 2c, were identical to their single-junction predecessors, except we annealed the $\mathrm{NiO}_{x}$ layer at $190{ }^{\circ} \mathrm{C}$ for 10 hours instead of $300{ }^{\circ} \mathrm{C}$ for 1 hour to prevent appreciable deterioration of the surface passivation layers in the underlying silicon cell (Supplementary Figure 10). We 
chose an amorphous silicon / crystalline silicon heterojunction solar cell design for the bottom cell because of its high $V_{0 c}$, which results from the separation of the highly recombination-active (ohmic) contacts from the silicon absorber bulk, and because its dominant performance-loss mechanism under the standard solar spectrum-parasitic absorption of blue light in the front amorphous silicon (a-Si:H) layers-is irrelevant in tandems.

The silicon cell fabrication process was adjusted to tune the silicon cells to the infrared spectrum that they receive in the tandem, as well as for compatibility with the spin-coated perovskite top cells. In particular, the a-Si:H layers on both sides were slightly thickened to enhance passivation and carrier collection (the resulting visible parasitic absorption is not detrimental in tandems) ${ }^{45}$. A wafer with a chemical-mechanical polished front surface was used to allow for top-cell spin coating, but the rear of wafer was textured to form random pyramids. The pyramids scatter weakly absorbed near-bandgap light, elongating its path length through the wafer and enhancing the cell's infrared EQE. An excellent rear reflector comprising a silicon nanoparticle (SiNP) / silver stack was also implemented ${ }^{46}$. The SiNP layer, which is atypical in silicon heterojunction solar cells, is used because of its low refractive index-with a porosity of approximately $60 \%$, its refractive index is 1.4 -and high transparency at wavelengths longer than $1000 \mathrm{~nm}^{46}$. Inserting a thick, low-refractive-index layer between the wafer and metal reflector increases the rear internal reflectance by reducing the fraction of light that reaches the lossy metal layer ${ }^{48}$, and a SiNP / silver reflector has a rear internal reflectance of over $99 \%{ }^{46,49}$. Finally, the front ITO layer was thinned to reduce infrared parasitic absorption since it does not need to play the role of antireflection coating in tandems and because, unlike in a single-junction silicon cell, the lateral conductivity of the front electrode need not be high.

In more detail, following the fabrication sequence, an $n$-type, $280-\mu \mathrm{m}$-thick, double-side polished, float-zone (FZ) silicon wafer was textured only on its rear side in an alkaline solution, resulting in the formation of random pyramids. Intrinsic and p-type a-Si:H films (7 and $15 \mathrm{~nm}$ thick, respectively) were first deposited by plasma-enhanced chemical vapor deposition on the textured (rear) side of the wafer, and intrinsic and $n$-type a-Si:H films ( 7 and $8 \mathrm{~nm}$ thick, respectively) were then deposited on the polished (front) side. A 20-nm-thick, highly transparent ITO layer was next sputtered on the front side through a shadow mask, defining $11 \mathrm{~mm} \times 11 \mathrm{~mm}$ square cells, to act as a recombination junction between the silicon and perovskite cells. A 20-nm-thick, highly transparent ITO layer was also deposited over the rear side through the same shadow mask, followed by a 300-nm-thick SiNP layer spray coated through a stainless-steel mesh to define local openings ${ }^{47}$, and finally, a 200-nm-thick silver layer. Figure $2 \mathrm{~b}$ shows a plan-view microscope image of the patterned SiNP layer before silver sputtering; the $5 \%$ uncoated area allows the silver to make direct electrical contact to the underlying ITO layer (Figure 2d), whereas the SiNPs in the remaining area (Figure 2e) enhance infrared conversion efficiency.

On its own, the silicon bottom cell has an efficiency well below $10 \%$ because of low FF caused by the high sheet resistance of the thin front ITO layer and lack of metal fingers, and because of low short-circuit current density $\left(J_{S c}\right)$ caused by the high reflectance of the planar front surface and lack of appropriate anti-reflection coating. The best $4 \mathrm{~cm}^{2}$ silicon heterojunction solar cell fabricated by the same lab with the same-but double-side-textured-wafers, adjusted deposition processes, and screen-printed silver 
fingers reached an NREL-certified efficiency of $21.4 \%$. A comparable $1 \mathrm{~cm}^{2}$ cell (as in the tandem) is expected to have an efficiency approximately $0.3 \%$ lower because of a $10 \mathrm{mV} V_{\text {oc }}$ loss from increased edge recombination, and a comparable cell with a planar front surface (as in the tandem) is expected to reach only $19-20 \%$.

Figure $2 \mathrm{f}$ displays the $\mathrm{J}-\mathrm{V}$ characteristic of the champion tandem cell, certified at NREL, with a $V_{\text {OC }}$ of $1.65 \mathrm{~V}, J_{\mathrm{sc}}$ of $18.1 \mathrm{~mA} / \mathrm{cm}^{2}$, and $F F$ of $79.0 \%$, resulting in an efficiency of $23.6 \%$ with a $1 \mathrm{~cm}^{2}$ aperture area and no hysteresis, as shown in Supplementary Figure 9 . The tandem was held at its maximum power point for over half an hour, under constant illumination, and maintained $23.6 \%$ efficiency. Supplementary Figure 11 shows performance metrics for our final batch of devices without IR reflector: $\mathrm{V}_{\mathrm{oc}}=1.64 \pm 0.02 \mathrm{~V}, \mathrm{~J}_{\mathrm{sc}}=$ $17.5 \pm 0.2 \mathrm{mAcm}^{-2}, \mathrm{FF}=79.9 \pm 1.0 \%$, and $\eta=22.8 \pm 0.4 \%$ and with IR reflectors $\mathrm{V}_{\mathrm{oc}}=1.64 \pm 0.01 \mathrm{~V}, \mathrm{~J}_{\mathrm{sc}}=18.2$ $\pm 0.2 \mathrm{mAcm}^{-2}, \mathrm{FF}=78.1 \pm 1.0 \%$, and $\eta=23.3 \pm 0.4 \%$. The high performance and narrow statistical distribution for these $1 \mathrm{~cm}^{2}$ cells - which are large-area amongst present perovskite devices-attests to the ability of the pulsed-CVD process to deposit a window layer that prevents pinholes and shunt pathways.

Figure $2 \mathrm{~g}$ shows the measured total absorbance (1-reflectance) and EQE of both sub-cells in the perovskite/silicon tandem solar cell. The figure has been divided into several (colored) regions to help visualize the tandem response and loss mechanisms. Integrating the EQE spectra over the AM 1.5G spectrum reveals that the perovskite top cell and silicon bottom cell generate $18.9 \mathrm{~mA} / \mathrm{cm}^{2}$ and $18.5 \mathrm{~mA} / \mathrm{cm}^{2}$, respectively. We note that the silicon cell EQE exceeds $90 \%$ between 800 and $875 \mathrm{~nm}$, which is much higher than the measured transmittance of the single-junction perovskite cell in Figure 1c. This high EQE results from a thinner ITO electrode $(20 \mathrm{~nm}$ between the silicon and perovskite in the tandem instead of $170 \mathrm{~nm}$ between the perovskite and glass in the single-junction cell) and reduced reflection due to the lack of an air interface in the tandem. Supplementary Figures 9 and 11 illustrate the efficacy of the SiNP rear reflector in increasing infrared absorption within the silicon wafer, corresponding to an increase in $J_{\mathrm{sc}}$ of about $1.5 \mathrm{~mA} / \mathrm{cm}^{2}$. Two main current losses are front-surface reflection (area above the total absorbance curve) and parasitic absorption (area between the total absorbance and EQE curves), which account for $4.8 \mathrm{~mA} / \mathrm{cm}^{2}$ and $4.5 \mathrm{~mA} / \mathrm{cm}^{2}$, respectively. To further improve the $J_{s c}$ of the tandem device, the easiest step would be to reduce front-surface reflection. Were it eliminated, the summed $J_{\text {sc }}$ would increase by $4.2 \mathrm{~mA} / \mathrm{cm}^{2}$. As parasitic absorption still exists, not all transmitted photons would be converted into electron-hole pairs. The short-wavelength parasitic absorption loss associated with the first pass through the layers at the front of the solar cell is $1.2 \mathrm{~mA} / \mathrm{cm}^{2}-0.7 \mathrm{~mA} / \mathrm{cm}^{2}$ from the ITO and $0.5 \mathrm{~mA} / \mathrm{cm}^{2}$ from the PCBM and $\mathrm{SnO}_{2} /$ ZTO bilayer, according to our optical simulations-and all of this would be gained as current in the top cell if the parasitic absorption were eliminated. The infrared parasitic absorption, which may occur in any layer in the tandem, appears to be large at $3.3 \mathrm{~mA} / \mathrm{cm}^{2}$, but this "loss" is misleading because not all of this current is available to be gained. Eliminating infrared parasitic absorption will result in a $J_{s c}$ gain (in the bottom cell) of less than half that value because-even assuming Lambertian light trapping-much of the light will escape out the front of the cell and contribute to the measured reflectance. 


\section{Improved Stability of Perovskite Solar Cells}

We have previously shown that ${ }^{38}$, in addition to acting as a highly transparent and conductive electrode, ITO-by virtue of its behavior as a diffusion barrier-can significantly increase the thermal and environmental stability of a perovskite solar cell by essentially trapping the volatile methylammonium cation ${ }^{50}$. The increased thermal stability of the thermodynamically favorable ${ }^{27}$ mixed CsFA perovskite compared to the pure methylammonium perovskite ${ }^{26}$, along with the dense, pinhole-free ALD $\mathrm{SnO}_{2} / \mathrm{ZTO}$ bilayer, should result in perovskite solar cells with even greater stability than previously reported. We tested the stability of single-junction CsFA mixed perovskite solar cells by operating $0.48 \mathrm{~cm}^{2}$-aperturearea devices at the maximum power point without additional encapsulation under continuous, one-sunequivalent, visible illumination with a sulfur plasma lamp. The test was performed in ambient conditions with an average room humidity of around $40 \%$ and the lamp heating the samples to $35^{\circ} \mathrm{C}$. Remarkably, the devices operated with minimal degradation in performance for over 1000 hours of testing, as shown in Figure 3a. In our previous study, small dust particles in the perovskite resulted in pinholes in the ITO encapsulation, creating a pathway for methylammonium evolution and causing eventual efficiency degradation ${ }^{38}$. In the present CsFA devices, however, no such pinhole-based degradation was apparent after 1000 hours of operation, speaking to the efficacy of the conformal ALD process to prevent pinhole formation and to the overall increased stability of the CsFA perovskite.
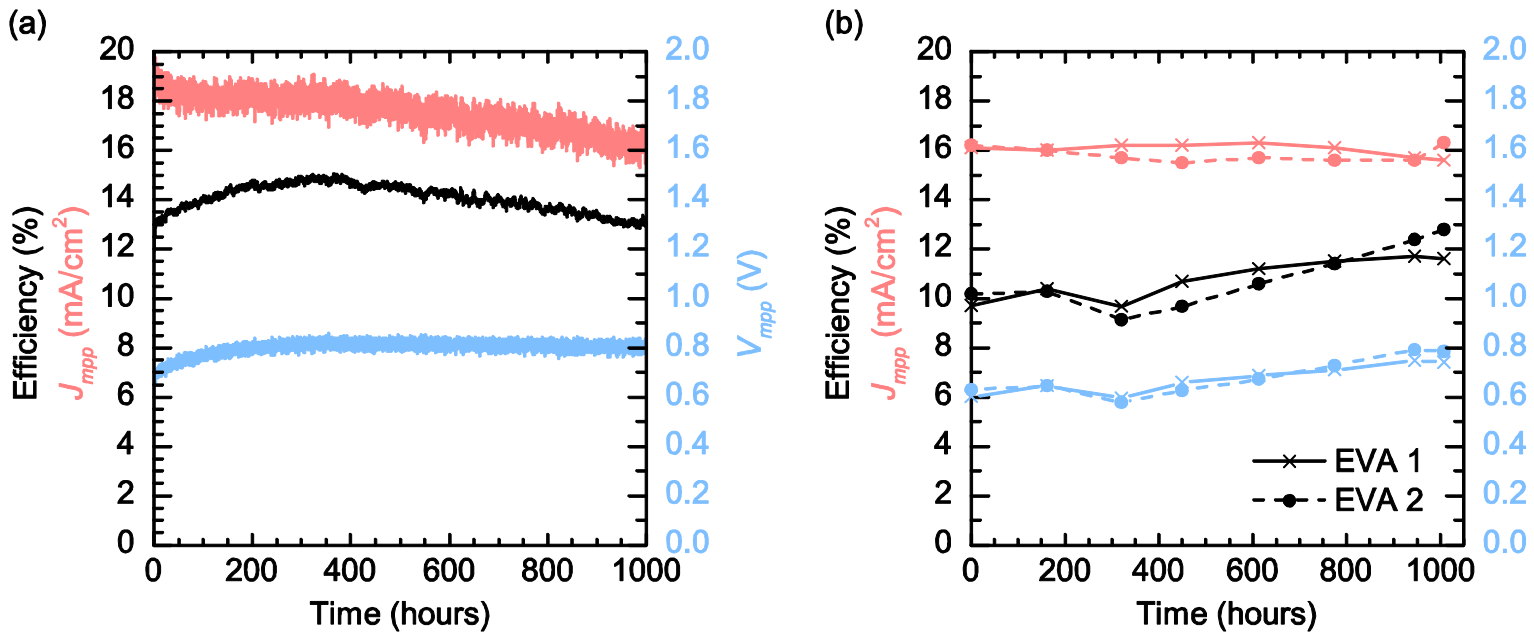

Figure 3. Stability of perovskite top cell. (a) Efficiency (black), $J_{M P P}$ (red), and $V_{M P P}$ (blue) of a singlejunction perovskite device with no additional encapsulation during 1000 hours of continuous maximumpower-point tracking, (b) efficiency (black), $J_{M P P}(r e d)$, and $V_{M P P}$ (blue) of a single-junction perovskite device packaged with EVA, glass, and a butyl rubber edge seal during damp-heat testing.

Although the cell in Figure 3a had the same efficiency after 1000 hours as at the start of the test, this efficiency was not constant over the testing period. As can be seen in Figure 3a, the rise in efficiency during the first 400 hours corresponds to an increase in voltage $\left(V_{\text {MPP }}\right)$, likely indicating the improvement of the $\mathrm{NiO} /$ perovskite interface or increased perovskite crystallinity. $V_{\text {MPp }}$ started at only a modest value but the lack of $V_{\text {MPP }}$ decay during the test is noteworthy. Falling current density $\left(J_{M P P}\right)$ is the culprit for the decrease 
in efficiency over the last 600 hours of the test. The exact cause of this decrease in $J_{\text {MPp }}$ is presently being studied, but potential causes are the lack of an edge seal or pinholes in the ITO layer caused by dust particles; either case would lead to evolution of the organic cation. However, both of these potential issues can be solved through proper device encapsulation. The vast majority of commercial silicon solar modules are encapsulated with the elastomeric polymer ethylene-vinyl acetate (EVA) and a glass cover sheet to prevent oxidation and moisture ingress, and thus to enable $>25$-year lifetimes. Lamination of EVA is typically performed at $110-150{ }^{\circ} \mathrm{C}$ for $30 \mathrm{~min}$ under mild vacuum. The increased thermal stability ${ }^{38}$ of our perovskite devices with the sputtered ITO electrode enables us to compare the stability of our devices directly to conventional silicon modules by packaging our devices using this industry-standard encapsulation process. We laminated single-junction perovskite devices between two sheets of glass with EVA at a curing temperature of $140{ }^{\circ} \mathrm{C}$ for 20 minutes. A butyl rubber edge seal was used to prevent moisture ingress.

In order to test the efficacy of this packaging, we performed the damp heat test described in the International Electrotechnical Commission (IEC) design qualification testing protocol 61215 for "Crystalline Silicon Terrestrial Photovoltaic (PV) Modules." These are accelerated lifetime tests with the goal of rigorously testing modules for the same failure mechanisms observed in the field in a much shorter time. The damp-heat test requires that the module operate at $85^{\circ} \mathrm{C}$ and $85 \%$ relative humidity for 1000 hours with no more than $10 \%$ degradation in performance. We performed this damp heat test on two packaged perovskite devices over the course of 6 weeks (1008 hours). The devices were taken out of the dark damp heat chamber once a week and measured with a maximum-power-tracking program until the efficiency stabilized. Figure $3 \mathrm{~b}$ shows the voltage, current, and efficiency at maximum power each week. Not only do the devices pass the damp heat test, they improve over the course of the test. While the efficiency of the devices is initially limited by poor $F F, V_{\text {MPP }}$ increases throughout the test, similar to under continuous illumination (Figure $3 a$ ). However, unlike in the continuous-illumination study, $J_{\text {MPP }}$ remains constant throughout the course of the damp-heat test, indicating that the packaging successfully addressed potential problems such as pinholes in the ITO and an improper edge seal.

\section{Conclusions}

An ALD or pulsed-CVD processed $\mathrm{SnO}_{2}$ /ZTO window layer has enabled the successful fabrication of perovskite solar cells with high efficiency and improved stability. These vapor processes produces a compact, conformal, uniform, and highly transparent $\mathrm{SnO}_{2} / \mathrm{ZTO}$ bilayer with efficient hole-blocking ability and sputter buffer layer properties, allowing for $1 \mathrm{~cm}^{2}$ devices with no pinholes. These devices have the thermal and ambient stability to be further sealed with industry standard encapsulation such as EVA and glass. In addition to being made as single-junction devices on glass, the same devices were fabricated on silicon solar cells with planar front surfaces to form two-terminal tandems. When the perovskite cells were coupled with silicon heterojunction bottom cells with an excellent rear reflector and a-Si:H and ITO layers adjusted for the exclusively infrared spectrum, the resulting tandem reached an efficiency of $23.6 \%$ with no hysteresis and stable maximum power over more than 30 minutes under illumination. This 
efficiency is well beyond that of both sub-cells, beyond that of the record single-junction perovskite cell, and approaching that of the record single-junction silicon cell. Performance-loss simulations suggest the efficiency can be increased further by widening the bandgap of the perovskite and reducing front-surface reflection, which will enable both higher matched current densities and higher voltage. Perovskite/silicon tandems with an ALD $\mathrm{SnO}_{2}$ /ZTO bilayer layer present a promising method to achieving industry standard operational lifetimes with pathways to raising efficiencies over $30 \%{ }^{19}$.

\section{Methods}

\section{Perovskite Device Fabrication.}

Semi-transparent perovskite devices were fabricated on patterned, $10 \Omega / \square$ glass from Xin Yan Technology. After cleaning with Extran, acetone, and isopropanol, the ITO glass was UV ozone cleaned for 15 minutes. A $1 \mathrm{M}$ solution of nickel nitrate hexahydrate (Sigma-Aldrich, puriss) and ethylenediamine (Sigma-Aldrich) in anhydrous ethylene glycol (Sigma-Aldrich) was spun on ITO-coated glass at $5000 \mathrm{rpm}$ for 50 seconds and annealed at $300{ }^{\circ} \mathrm{C}$ for 1 hour. The $\mathrm{NiO}_{x}$ films were quickly taken into a dry air box where the CsFA perovskite was deposited from a stoichiometric solution containing Csl (Sigma-Aldrich, 99.99\% trace metals), formamidinium iodide (Dyesol), $\mathrm{Pbl}_{2}$ ( $\mathrm{TCl}$ ), and $\mathrm{PbBr}_{2}$ (Sigma-Aldrich, 96\%) in a mixture of $\mathrm{N}, \mathrm{N}$-dimethylformamide (DMF, Sigma-Aldrich) and dimethyl sulfoxide (DMSO, Sigma-Aldrich). The solution was deposited through a $0.2 \mu \mathrm{m}$ PTFE filter and spun at $1000 \mathrm{rpm}$ for 11 seconds, followed by 6000 rpm for 30 seconds. During spin coating, chlorobenzene was quickly dispensed 5 seconds prior to the end of the spin process as an antisolvent to assist perovskite crystallization. The films were annealed on a hot plate at $50{ }^{\circ} \mathrm{C}$ for 1 minute and then annealed at $100{ }^{\circ} \mathrm{C}$ for 30 minutes. This deposition method was adapted from Chenyi et $\mathrm{al}^{27}$. Next, we thermally evaporated $1 \mathrm{~nm}$ of LiF and a thin $10 \mathrm{~nm}$ layer of PCBM. Then, we deposited $4 \mathrm{~nm}$ of stoichiometric $\mathrm{SnO}_{2}$ with pulsed-CVD at $100{ }^{\circ} \mathrm{C}$ on top of the PCBM, followed by $2 \mathrm{~nm}$ of zinc tin oxide. Tin oxide and zinc oxide pulsed-CVD processes were developed on an Arradiance GEMStar-6 ALD system at $100{ }^{\circ} \mathrm{C}$. The $\mathrm{SnO}_{2}$ pulsed-CVD cycle consisted of the processing sequence: $5 \mathrm{sec}$ purge $\left(30 \mathrm{sccm} \mathrm{N}\right.$ ), $1.5 \mathrm{sec}$ TDMASn pulse ( $\left.30 \mathrm{sccm} \mathrm{N} \mathrm{N}_{2}\right), 5 \mathrm{sec}$ purge $(90 \mathrm{sccm} \mathrm{N}$ ), $1 \mathrm{sec}$ deionized water pulse ( $90 \mathrm{sccm} \mathrm{N} \mathrm{N}_{2}$ ) and $5 \mathrm{sec}$ of purging $\left(90 \mathrm{sccm} \mathrm{N} \mathrm{N}_{2}\right)(5 \mathrm{sec} / 1.5 \mathrm{sec} / 5 \mathrm{sec} / 1 \mathrm{sec} / 5 \mathrm{sec})$. The door and body temperature was maintained at $100{ }^{\circ} \mathrm{C}$ for the hot-wall reactor while the manifold temperature was $115{ }^{\circ} \mathrm{C}$ with a precursor temperature of $60{ }^{\circ} \mathrm{C}$. Pulsed-CVD of zinc oxide was grown at $100{ }^{\circ} \mathrm{C}$ using diethyl zinc (DEZ) and water with the processing sequence: $100 \mathrm{msec} / 5 \mathrm{sec} / 1 \mathrm{sec} / 5 \mathrm{sec}$ with a constant $90 \mathrm{sccm} \mathrm{N} \mathrm{N}_{2}$ flow. The reactor temperatures were the same as the tin oxide process, but the DEZ precursor was unheated. Please note that ALD can be performed instead of pulsed-CVD above. See Supplementary Tables 1-4 for details of the ALD and pulsed-CVD process parameters. For the semitransparent and monolithic tandem devices, $150 \mathrm{~nm}$ of ITO was deposited through DC sputtering. The sputter deposition of ITO films in the work were performed as previously described in the supplemental section of Bush et al. ${ }^{38}$ An ITO witness sample on glass has a mobility of $43 \mathrm{~cm}^{2} / \mathrm{Vs}$ and a carrier concentration of $3.5 \times 10^{20} \mathrm{~cm}^{-3}$. We finished the device stack with an evaporated or sputtered silver metal electrode around the perimeter of the $1 \mathrm{~cm}^{2}$ device area to minimize series resistance and subsequently 
evaporated $150 \mathrm{~nm}$ of LiF as a second anti-reflection coating. For the damp heat stability testing, the single-junction solar cells were packaged between top and bottom EVA encapsulants and two sheets of 3-mm-thick glass. The butyl rubber edge seal was placed as a frame on the outer edge of the glass during assembly. The package got pressed with 1000 mbar pressure at $140{ }^{\circ} \mathrm{C}$ for 20 minutes for the edge seal to soften and the encapsulant to cure.

\section{Silicon Device Fabrication.}

An $n$-type, 280- $\mu$ m-thick, double-side polished, float-zone wafer was used as the starting substrate. A 250-nm-thick silicon nitride layer was deposited by plasma-enhanced chemical vapor deposition (PECVD) in an AMAT P5000 tool on one side of the wafer as a protective coating, and the wafer was then textured on the uncoated side in potassium hydroxide to reveal random pyramids. After removing the nitride coating in diluted hydrofluoric acid, the wafer was cleaned in piranha and RCA-B solutions, and the oxide was removed in buffered oxide etchant prior to deposition of amorphous silicon (a-Si:H) layers. Intrinsic and p-type a-Si:H films ( 7 and $15 \mathrm{~nm}$ thick, respectively) were first deposited by PECVD on the textured (rear) side of the wafer, and intrinsic and n-type a-Si:H films ( 7 and $8 \mathrm{~nm}$ thick, respectively) were then deposited on the polished (front) side. A 20-nm-thick indium tin oxide (ITO) layer was sputtered from a $90 / 10 \mathrm{In}_{2} \mathrm{O}_{3} / \mathrm{SnO}_{2}$ in an MRC 944 tool on the polished side of the wafer through a shadow mask to define square cells $11 \mathrm{~mm}$ on a side. A 20-nm-thick ITO layer was also sputtered over the textured surface through the same shadow mask. The front ITO layer was deposited using a 2.3/100 oxygen/argon mixture, which results in films with electron densities and mobilities of approximately $5 \times 10^{20} \mathrm{~cm}^{-3}$ and $25 \mathrm{~cm}^{2} / \mathrm{Vs}$, respectively after annealing at $200{ }^{\circ} \mathrm{C}$; in contrast, the rear ITO layer was deposited using a 4.1/100 oxygen/argon mixture, which results in films with electron densities and mobilities of approximately $2 \times 10^{20} \mathrm{~cm}^{-3}$ and $25 \mathrm{~cm}^{2} / \mathrm{Vs}$, respectively, after annealing at $200{ }^{\circ} \mathrm{C}$. The textured surface was subsequently coated with a 300-nm-thick silicon nanoparticle layer that was spray coated through a stainless-steel mesh (in contact with the wafer) to define local openings occupying approximately $5 \%$ of the total area. The nanoparticles were synthesized and deposited in a custom tool that uses a flow-through plasma process to nucleate nanoparticles from silane gas and deposit them via acceleration through a nozzle toward a substrate. The wafer was next annealed at $200^{\circ} \mathrm{C}$ for $20 \mathrm{~min}$ to partially oxidize the nanoparticles, and a 200-nm-thick silver layer was sputtered through the shadow mask to cover the textured surface, finishing the cell.

\section{Device Characterization.}

Current-voltage measurements were performed using a Keithley model 2400 digital source meter. A $300 \mathrm{~W}$ xenon lamp (Oriel) solar simulator was used to irradiate semi-transparent devices from the bottom glass side. To irradiate tandems and semi-transparent devices from the top, an Oriel Sol3A solar simulator was used. To negate spectral mismatch between our reference KG5 diode and the response of the perovskite and silicon solar cells, the lamp was calibrated to match the integrated photocurrent calculated by EQE. For the semi-transparent devices, the $J-V$ curves were measured from forward to reverse bias with a $0.1 \mathrm{~V} / \mathrm{s}$ scan rate. The semi-transparent devices were initially tested using a maximum power tracking program which is a perturb-and-measure program with voltage steps of $5 \mathrm{mV}$. Once the device 
efficiency has stabilized for at least 10 minutes, a J-V scan is taken. For the monolithic tandem devices, both forward-to-reverse and reverse-to-forward scans were measured at a rate of $0.12 \mathrm{~V} / \mathrm{s}$. Reported values for efficiency were all evaluated based on steady maximum power point operation for a minimum of a minute. The opaque cells and semi-transparent cells were illuminated through 0.12 and $0.39 \mathrm{~cm}^{2}$ aperture areas, respectively. The perovskite/silicon tandems all had an aperture area of $1 \mathrm{~cm}^{2}$. The external quantum efficiency (EQE) was recorded as a function of the wavelength using a Keithley model 236. A $100 \mathrm{~W}$ tungsten lamp (Newport) was used as the excitation source and focused through a Princeton Instruments SpectraPro 150 monochromator. The monochromatic light was chopped at around $73 \mathrm{~Hz}$ and Stanford Research Systems SR830 model lock-ins were used to monitor the perovskite signal at the chopping frequency. Data were averaged for 5 seconds at each wavelength. Each individual subcell in the tandem must be electrically isolated to obtain an EQE spectrum. We light-biased the silicon sub-cell with a $980 \mathrm{~nm}$ laser diode from ThorLabs and the perovskite sub-cell with a white light LED array to measure the EQE of the perovskite and silicon sub-cells, respectively. No white-light bias was used during the EQE measurement of the single-junction perovskite devices. To measure the unpackaged stability under continuous illumination, devices were tested under a sulfur plasma lamp from LG (6000 K blackbody). The device is monitored at maximum power point using electronics from Science Wares Inc. The surface temperature of the devices during the test is $35^{\circ} \mathrm{C}$, as measured with a temperature probe. The packages were placed in an $85{ }^{\circ} \mathrm{C}$ and $85 \%$ relative humidity chamber and were taken out every week for performance measurements taken at room temperature. All devices were tested under a 1-sun, Xenon arc-lamp from Newport, model 94023A. The device performances were tested using a Keithley 2400 and a maximum-power-point-tracking program written in LABVIEW to measure stable device performance.

Correspondence to Zachary C. Holman and Michael D. McGehee

\section{Acknowledgments}

The authors thank Mehdi Leilaeioun and Kate Fisher for assistance with silicon cell fabrication and simulation. The information, data, or work presented herein was funded in part by the U.S. Department of Energy (DOE) Sunshot NextGen III program under award number DE-EE0006707, the National Science Foundation (NSF) and Department of Energy under NSF Cooperative Agreement No. EEC-1041895, the Research Corporation for Science Advancement through Scialog Collaborative Innovation Award Number 23460, and the National Research Foundation Singapore through the Singapore MIT Alliance for Research and Technology's Low Energy Electronic Systems research program. K.A.B. is supported by the NSF Graduate Research Fellowship Program under Grant No. DGE-114747. The optical measurements were performed in part at the Stanford Nanofabrication Facility's nSiL lab, which is funded by NSF award ARI0963061. AFM and SEM were performed at the Stanford Nano Shared Facilities (SNSF). We appreciate those who provided supplies for device encapsulation: Jane Kapur (Dupont) for Surlyn, Lori Postak (Quanex) for Solargain edge tape, Tim Orfley (Corning) for eagle glass, and Steve Ebers and Sandra Lee (Ulbrich Solar Technologies) for bus ribbon.

\section{Author Contributions}


K.B. led the fabrication of perovskite solar cell, A.P. performed the ALD process for the window layer on perovskite solar cell, Z.Y. led the fabrication of silicon heterojunction solar cell, M.B. assisted the fabrication of silicon nanoparticle rear reflector. R.C. packaged devices. D.M. initiated the perovskite development. R.H. developed NiOx layer. C.B., J.M., T.L. and I.M. aided in project ideation and planning. M.M. assisted in semi-transparent-perovskite fabrication. N.R. performed AFM measurements. R.P. performed transfer-matrix optical modelling. S.S. assisted in ALD work. D.H. assisted in packaging and stability testing. W.M. and F.M. assisted in ITO deposition. K.B., A.P., Z.Y., and Z.H. wrote the manuscript, and all the rest discussed and reviewed the manuscript.

\section{Additional information}

The data that support the plots within this paper and other findings of this study are available from the corresponding author upon reasonable request

\section{Competing interests}

The authors declare no competing financial interests.

\section{References}

1. NREL Efficiency Table Rev. 08-08-2016. (2016). at <http://www.nrel.gov/ncpv/images/efficiency_chart.jpg>

2. Wolf, S. De et al. Organometallic Halide Perovskites : Sharp Optical Absorption Edge and its Relation to Photovoltaic Performance. J. Phys. Chem. Lett. 5, 1035-1039 (2014).

3. Stranks, S. D. et al. Electron-Hole Diffusion Lengths Exceeding. Science 342, 341-344 (2014).

4. Brandt, R. E., Stevanović, V., Ginley, D. S. \& Buonassisi, T. Identifying defect-tolerant semiconductors with high minority carrier lifetimes: Beyond hybrid lead halide perovskites. MRS Commun. 5, 265-275 (2015).

5. Noh, J. H., Im, S. H., Heo, J. H., Mandal, T. N. \& Seok, S. Il. Chemical management for colorful, efficient, and stable inorganic-organic hybrid nanostructured solar cells. Nano Lett. 13, 17641769 (2013).

6. Bailie, C. D. et al. Semi-transparent perovskite solar cells for tandems with silicon and CIGS. Energy Environ. Sci. 8, 956-963 (2014).

7. Todorov, T., Gershon, T., Gunawan, O., Sturdevant, C. \& Guha, S. Perovskite-kesterite monolithic tandem solar cells with high open-circuit voltage. Appl. Phys. Lett. 105, 173902 (2014).

8. Mailoa, J. P. et al. A 2-terminal perovskite/silicon multijunction solar cell enabled by a silicon tunnel junction. Appl. Phys. Lett. 106, 121105 (2015).

9. Löper, P. et al. Organic-inorganic halide perovskite/crystalline silicon four-terminal tandem solar 
cells. Phys. Chem. Chem. Phys. 17, 1619-1629 (2015).

10. Albrecht, S. et al. Monolithic perovskite/silicon-heterojunction tandem solar cells processed at low temperature. Energy Environ. Sci. 9, 81-88 (2016).

11. Werner, J. et al. Sputtered rear electrode with broadband transparency for perovskite solar cells. Sol. Energy Mater. Sol. Cells 141, 407-413 (2015).

12. Kranz, L. et al. High-Efficiency Polycrystalline Thin Film Tandem Solar Cells. J. Phys. Chem. Lett. 6, 2676-2681 (2015).

13. Yang, Y. M. et al. Multilayer Transparent Top Electrode for Solution Processed Perovskite/Cu(In,Ga)(Se,S)2 Four Terminal Tandem Solar Cells. ACS Nano 9, 7714-21 (2015).

14. Chen, B. et al. Efficient Semitransparent Perovskite Solar Cells for 23.0\%-Efficiency Perovskite/Silicon Four-Terminal Tandem Cells. Adv. Energy Mater. 6, 1-7 (2016).

15. Werner, J. et al. Efficient Monolithic Perovskite/Silicon Tandem Solar Cell with Cell Area $>1 \mathrm{~cm} 2$. J. Phys. Chem. Lett. 7, 161-166 (2016).

16. Yang, Z. et al. Stable Low-Bandgap Pb-Sn Binary Perovskites for Tandem Solar Cells. Adv. Mater. 28, 8990-8997 (2016).

17. Fu, F. et al. Low-temperature-processed efficient semi-transparent planar perovskite solar cells for bifacial and tandem applications. Nat. Commun. 6, 8932 (2015).

18. Eperon, G. E. et al. Perovskite-perovskite tandem photovoltaics with ideal bandgaps. Science. 9717, 1-9 (2016).

19. Lal, N. N., White, T. P. \& Catchpole, K. R. Optics and light trapping for tandem solar cells on silicon. IEEE J. Photovoltaics 4, 1380-1386 (2014).

20. Bailie, C. D. \& McGehee, M. D. High-efficiency tandem perovskite solar cells. MRS Bull. 40, 681686 (2015).

21. Ginley, D. S., Hosono, H. \& Paine, D. C. Handbook of transparent conductors. Handbook of Transparent Conductors (2011). doi:10.1007/978-1-4419-1638-9

22. Liao, L. S. et al. Ion-beam-induced surface damages on tris-(8-hydroxyquinoline) aluminum. Appl. Phys. Lett. 75, 1619 (1999).

23. Leijtens, T. et al. Stability of Metal Halide Perovskite Solar Cells. Adv. Energy Mater. 5, 1-23 (2015).

24. Liu, P. et al. Interfacial electronic structure at the CH3NH3PbI3 / MoOx interface. Appl. Phys. Lett. 106, 193903 (2015).

25. Yang, W. S. et al. High-performance photovoltaic perovskite layers fabricated through intramolecular. Science. 348, 1234-1237 (2015).

26. Lee, J. W. et al. Formamidinium and cesium hybridization for photo- and moisture-stable 
perovskite solar cell. Adv. Energy Mater. 5, 1-9 (2015).

27. Yi, C. et al. Entropic stabilization of mixed A-cation ABX 3 metal halide perovskites for high performance perovskite solar cells. Energy Environ. Sci. 9, 656-662 (2016).

28. Liu, X. et al. Spray Reaction Prepared FA1-xCsxPbl3 Solid Solution as Light Harvester for Perovskite Solar Cells with Improved Humidity Stability. RSC Adv. 6, 14792-14798 (2016).

29. McMeekin, D. P. et al. A mixed-cation lead mixed-halide perovskite absorber for tandem solar cells. Science. 351, 151-155 (2016).

30. Saliba, M. et al. Cesium-containing triple cation perovskite solar cells: improved stability, reproducibility and high efficiency. Energy Environ. Sci. 9, 1989-1997 (2016).

31. Bakke, J. R., Pickrahn, K. L., Brennan, T. P. \& Bent, S. F. Nanoengineering and interfacial engineering of photovoltaics by atomic layer deposition. Nanoscale 3, 3482-3508 (2011).

32. Palmstrom, A. F., Santra, P. K. \& Bent, S. F. Atomic layer deposition in nanostructured photovoltaics: tuning optical, electronic and surface properties. Nanoscale 7, 12266-12283 (2015).

33. Kim, B.-J. et al. Highly efficient and bending durable perovskite solar cells: toward wearable power source. Energy Environ. Sci. 8, 916-921 (2015).

34. Baena, J. P. C. et al. Highly efficient planar perovskite solar cells through band alignment engineering. Energy Environ. Sci. 8, 2928-2934 (2015).

35. Zhu, Z. et al. Enhanced Efficiency and Stability of Inverted Perovskite Solar Cells Using Highly Crystalline SnO2 Nanocrystals as the Robust Electron-Transporting Layer. Adv. Mater. 28, 64786484 (2016).

36. You, J. et al. Improved air stability of perovskite solar cells via solution-processed metal oxide transport layers. Nat. Nanotechnol. 11, 1-8 (2015).

37. Kim, J. H. et al. High-Performance and Environmentally Stable Planar Heterojunction Perovskite Solar Cells Based on a Solution-Processed Copper-Doped Nickel Oxide Hole-Transporting Layer. Adv. Mater. 27, 695-701 (2015).

38. Bush, K. A. et al. Thermal and Environmental Stability of Semi-Transparent Perovskite Solar Cells for Tandems Enabled by a Solution-Processed Nanoparticle Buffer Layer and Sputtered ITO Electrode. Adv. Mater. 28, 3937-3943 (2016).

39. Mullings, M. N., Hägglund, C. \& Bent, S. F. Tin oxide atomic layer deposition from tetrakis(dimethylamino)tin and water. J. Vac. Sci. Technol. A Vacuum, Surfaces, Film. 31, 61503 (2013).

40. Guziewicz, E. et al. ALD grown zinc oxide with controllable electrical properties. Semicond. Sci. Technol. 27, 74011 (2012).

41. Despeisse, M. et al. Resistive interlayer for improved performance of thin film silicon solar cells 
on highly textured substrate. Appl. Phys. Lett. 96, 10-13 (2010).

42. Larson, B. W. et al. Thermal $[6,6]->[6,6]$ Isomerization and Decomposition of PCBM (Phenyl-C61butyric Acid Methyl Ester). Chem. Mater. 26, 2361-2367 (2014).

43. Mullings, M. N. et al. Thin film characterization of zinc tin oxide deposited by thermal atomic layer deposition. Thin Solid Films 556, 186-194 (2014).

44. Hägglund, C. et al. Growth, intermixing, and surface phase formation for zinc tin oxide nanolaminates produced by atomic layer deposition. J. Vac. Sci. Technol. A Vacuum, Surfaces, Film. 34, 21516 (2016).

45. Holman, Z. C. et al. Current Losses at the Front of Silicon Heterojunction Solar Cells. IEEE J. Photovoltaics 2, 7-15 (2012).

46. Boccard, M., Firth, P., and Holman, Z. C. Low-refractive-index nanoparticle interlayers to reduce parasitic absorption in metallic reflectors of solar cells (In preparation).

47. Holman, Z. C. \& Kortshagen, U. R. A flexible method for depositing dense nanocrystal thin films: impaction of germanium nanocrystals. Nanotechnology 21, 335302 (2010).

48. Holman, Z. C. et al. Infrared light management in high-efficiency silicon heterojunction and rearpassivated solar cells. J. Appl. Phys. 113, 13107 (2013).

49. Holman, Z. C., De Wolf, S. \& Ballif, C. Improving metal reflectors by suppressing surface plasmon polaritons: a priori calculation of the internal reflectance of a solar cell. Light Sci. Appl. 2, 1-6 (2013).

50. Kim, I. S. \& Martinson, A. B. F. Stabilizing hybrid perovskites against moisture and temperature via non-hydrolytic atomic layer deposited overlayers. J. Mater. Chem. A 3, 20092-20096 (2015). 


\section{Supplementary Information}

\section{6\%-Efficient Monolithic Perovskite/Silicon Tandem Solar Cells with Improved Stability}

Kevin A. Bush ${ }^{\dagger 1}$, Axel F. Palmstrom ${ }^{\dagger 1}$, Zhengshan J. Yu ${ }^{\dagger 2}$, Mathieu Boccard ${ }^{2}$, Rongrong Cheacharoen ${ }^{1}$, Jonathan P. Mailoa ${ }^{3}$, David P. McMeekin ${ }^{4}$, Robert L. Z. Hoye ${ }^{3}$, Colin D. Bailie ${ }^{1}$, Tomas Leijtens ${ }^{1}$, lan Marius Peters ${ }^{3}$, Maxmillian C. Minichetti ${ }^{1}$, Nicholas Rolston ${ }^{1}$, Rohit Prasanna ${ }^{1}$, Sarah Sofia ${ }^{3}$, Duncan Harwood ${ }^{5}$, Wen $\mathrm{Ma}^{6}$, Farhad Moghadam ${ }^{6}$, Henry J. Snaith ${ }^{4}$, Tonio Buonassisi ${ }^{3}$, Zachary C. Holman*2, Stacey F. Bent ${ }^{1}$, and Michael D. McGehee*1

${ }^{1}$ Stanford University, Stanford, 94305, USA.

${ }^{2}$ Arizona State University, Tempe, 85281, USA.

${ }^{3}$ Massachusetts Institute of Technology, Cambridge, 02139, USA.

${ }^{4}$ University of Oxford, Oxford, UK.

${ }^{5}$ D2 Solar LLC, San Jose, 95131, USA.

${ }^{6}$ SunPreme, Sunnyvale, 94085, USA.

${ }^{\dagger}$ Authors contributed equally to this work

Zachary.holman@asu.edu, Mmcgehee@stanford.edu

\section{Supplementary Tables:}

Supplementary Table 1: Tin oxide growth processes at $100{ }^{\circ} \mathrm{C}$

\begin{tabular}{|c|c|c|c|c|c|c|}
\hline Process & $\begin{array}{l}\text { Purge (s) at } \\
30 \mathrm{sccm} \mathrm{N} \mathrm{N}_{2}\end{array}$ & $\begin{array}{c}\text { Metal Organic } \\
\text { Pulse (s) at } 30 \\
\quad \text { sccm N } N_{2}\end{array}$ & $\begin{array}{c}\text { Metal Organic } \\
\text { Purge (s) at } 90 \\
\quad \text { sccm N }\end{array}$ & $\begin{array}{c}\text { Oxidizer } \\
\text { Pulse (s) at } \\
90 \mathrm{sccm} \mathrm{N}_{2}\end{array}$ & $\begin{array}{c}\text { Oxidizer } \\
\text { Purge (s) at 90 } \\
\text { sccm } \mathrm{N}_{2}\end{array}$ & $\begin{array}{c}\text { Growth Rate } \\
\text { (Å/cyc) }\end{array}$ \\
\hline ALD $\mathrm{SnO}_{2}$ & 5 & 1.5 & 30 & 1 & 30 & 1.2 \\
\hline \begin{tabular}{|c|} 
Pulsed- \\
CVD SnO $_{2}$
\end{tabular} & 5 & 1.5 & 5 & 1 & 5 & $1.8^{*}$ \\
\hline
\end{tabular}

* Effective growth rate with parasitic CVD contributions. 
Supplementary Table 2: Zinc oxide growth processes at $100{ }^{\circ} \mathrm{C}$ with constant $90 \mathrm{sccm} \mathrm{N}$ flow

\begin{tabular}{|c|c|c|c|c|c|}
\hline Process & $\begin{array}{c}\text { Metal Organic } \\
\text { Pulse (s) }\end{array}$ & $\begin{array}{c}\text { Metal Organic } \\
\text { Purge (s) }\end{array}$ & $\begin{array}{c}\text { Oxidizer Pulse } \\
\text { (s) }\end{array}$ & $\begin{array}{c}\text { Oxidizer Purge } \\
\text { (s) }\end{array}$ & $\begin{array}{c}\text { Growth Rate } \\
\text { (Å/cyc) }\end{array}$ \\
\hline ALD ZnO & 0.1 & 30 & 1 & 30 & 2.0 \\
\hline Pulsed-CVD ZnO & 0.1 & 5 & 1 & 5 & 3.0 \\
\hline
\end{tabular}

* Effective growth rate with parasitic CVD contributions.

Supplementary Table 3: Zinc tin oxide supercycle process

\begin{tabular}{|c|c|c|}
\hline Process & $\mathrm{SnO}_{2}$ Cycles & ZnO Cycles \\
\hline ZTO supercycle & 3 & 3 \\
\hline
\end{tabular}

Supplementary Table 4: Reactor temperature setpoints

\begin{tabular}{|c|c|c|c|c|c|}
\hline Chamber Temp & Door Temp & Manifold Temp & $\begin{array}{c}\text { TDMASn } \\
\text { Bubbler Temp }\end{array}$ & $\begin{array}{c}\text { DEZ Bubbler } \\
\text { Temp }\end{array}$ \\
\hline $\begin{array}{c}\text { Parameter } \\
\text { Setpoint }\end{array}$ & $100^{\circ} \mathrm{C}$ & $100^{\circ} \mathrm{C}$ & $115^{\circ} \mathrm{C}$ & $60^{\circ} \mathrm{C}$ & Unheated \\
\hline
\end{tabular}

\section{Supplementary Figures:}

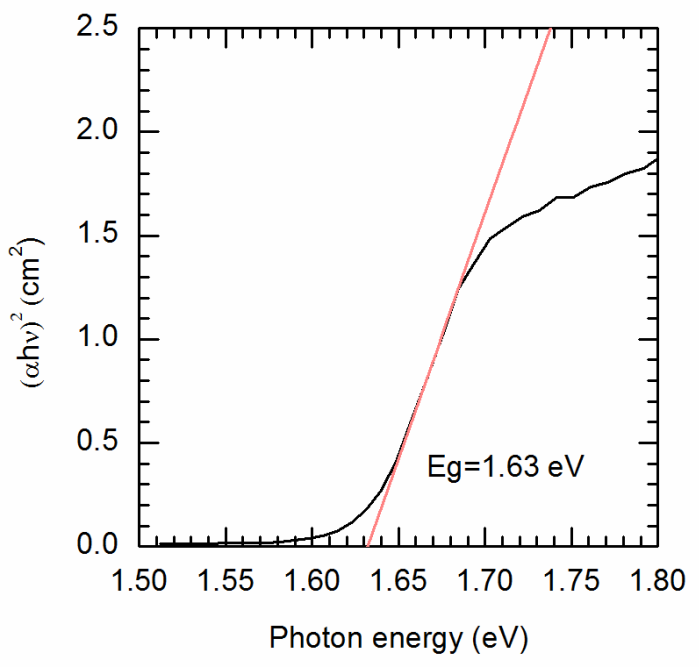

Supplementary Figure 1. Tauc plot of $\mathrm{Cs}_{0.17} \mathrm{FA}_{0.83} \mathrm{~Pb}\left(\mathrm{Br}_{0.17} \mathrm{l}_{0.83}\right)_{3}$ perovskite top cell showing bandgap of $1.63 \mathrm{eV}$. 

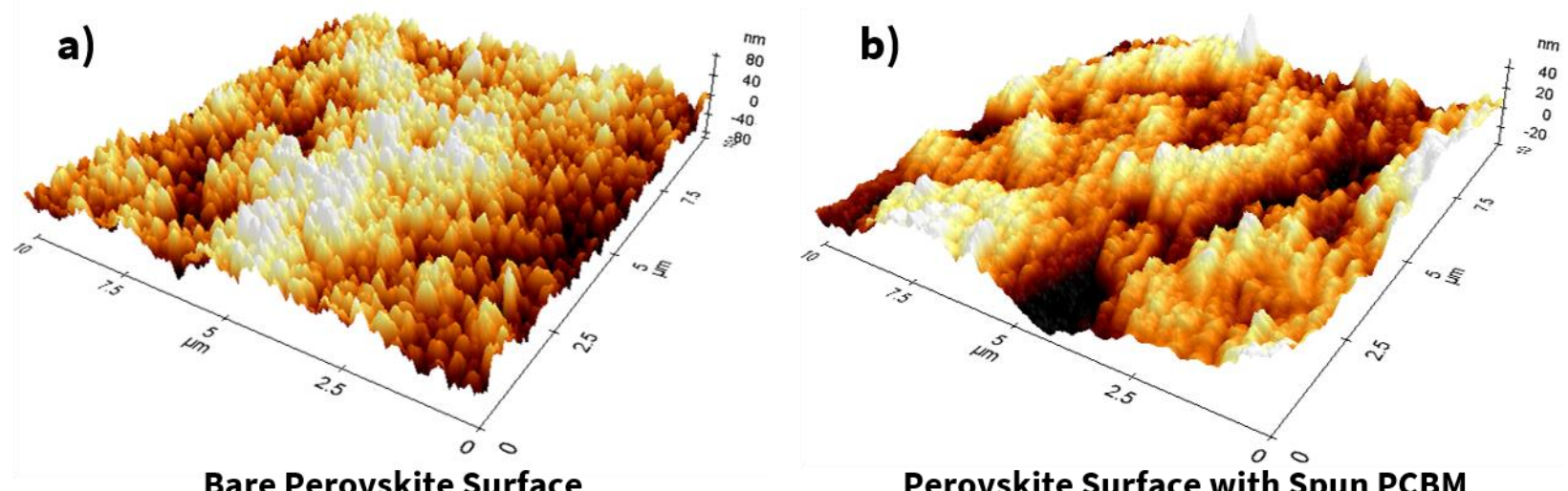

Bare Perovskite Surface
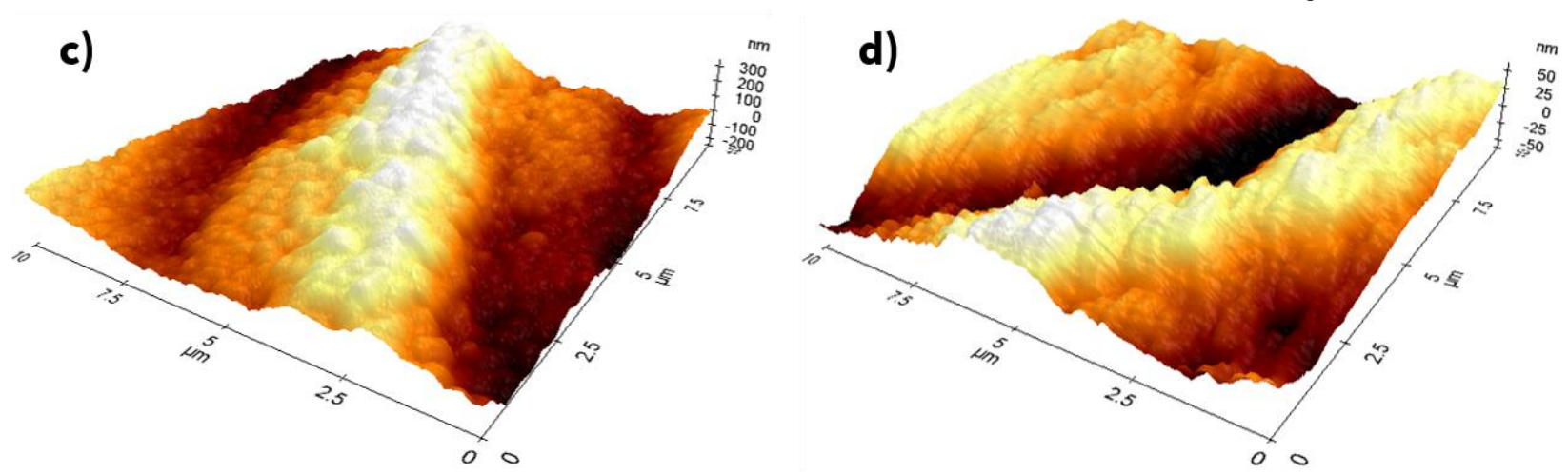

Supplementary Figure 2. Atomic force microscopy (AFM) images of CsFA perovskite surface before and after spinning $50 \mathrm{mg} / \mathrm{mL}$ PCBM in chlorobenzene onto the perovskite surface. Figures (a) $\left(R_{\mathrm{q}}=23.5 \mathrm{~nm}\right.$, $\left.R_{z}=166.7 \mathrm{~nm}\right)$ and $(c)\left(R_{q}=132.4 \mathrm{~nm}, R_{z}=586.5 \mathrm{~nm}\right)$ show the high degree of surface roughness of the bare perovskite film. Figures (b) $\left(R_{q}=6.9 \mathrm{~nm}, R_{z}=83.2 \mathrm{~nm}\right)$ and (d) $\left(R_{q}=25.3 \mathrm{~nm}, R_{z}=121.2 \mathrm{~nm}\right)$ show how spinning PCBM onto the surface decreases the roughness slightly, but ultimately cannot planarize the surface. The lack of planarization leads to the troughs being filled by a thick layer of PCBM and the peaks being left exposed. 

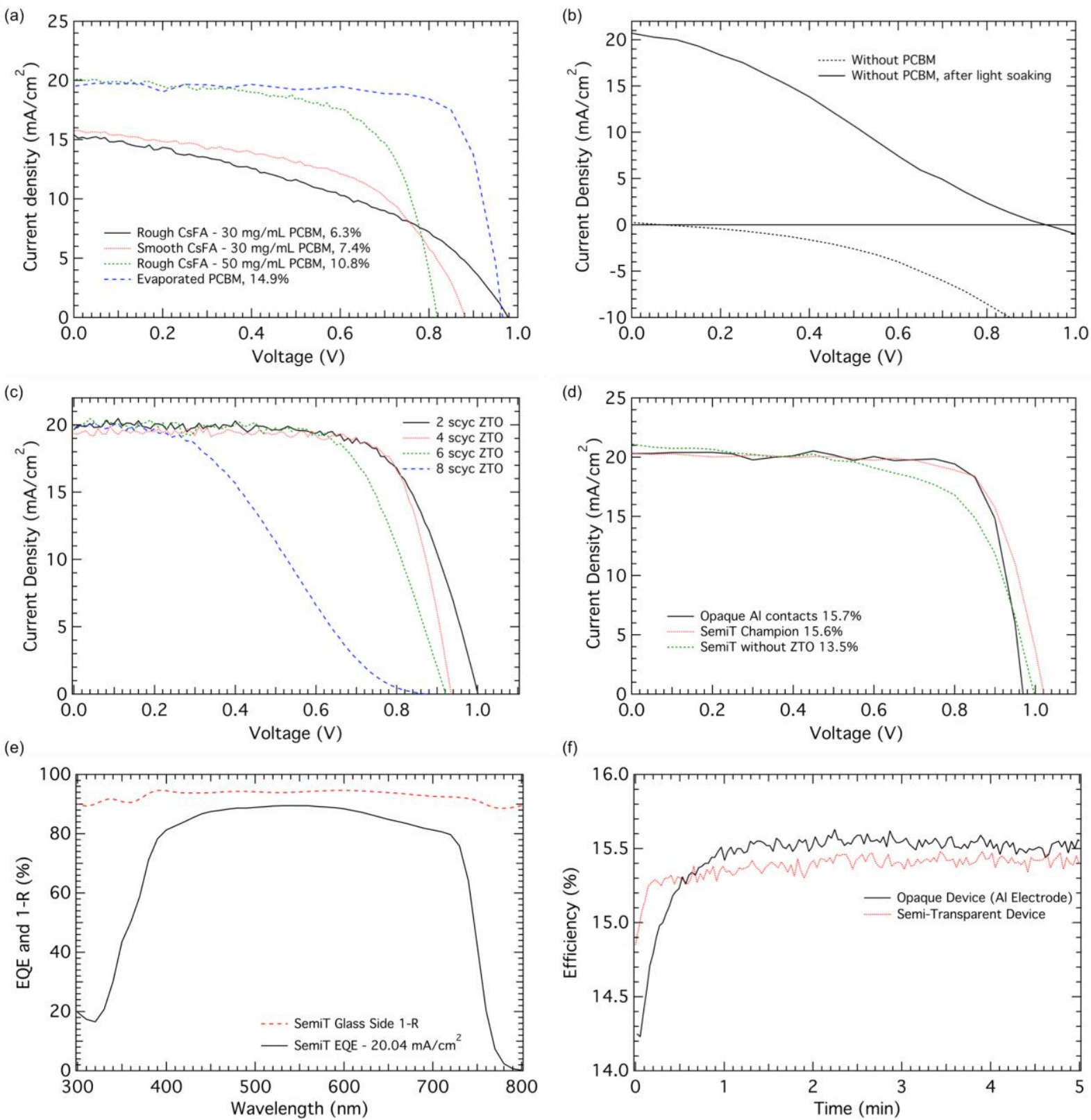

Supplementary Figure 3. (a) J-V scans of single-junction perovskite devices showing performance is best when heterojunction contacts are deposited through a conformal coating process, such as evaporation. The poor surface coverage from spin coating (Supplementary Figure 1) leads to decreased performance in comparison. The "smooth CsFA" refers to a thinner film with slightly decreased surface roughness. The higher concentration of PCBM creates a thicker layer of PCBM and shows improved device performance, but thicker PCBM is not ideal for maximizing transmission. (b) J-V scan of device without PCBM layer between perovskite and $\mathrm{ALD} \mathrm{SnO}_{2}$ layers. The large initial extraction barrier can be largely overcome by light soaking for over 30 minutes and holding in forward bias. But regardless of preconditioning, the PCBM layer is necessary to enable efficient electron extraction. (c) ZTO thickness, deposited in a repeating supercycle (scyc) on top of $4 \mathrm{~nm}$ of $\mathrm{SnO}_{2}$, was varied in order to achieve the optimal electron extraction properties. While $2 \mathrm{~nm}$ consistently led to higher $V_{\mathrm{OC}}$, the higher $F F$ of $4 \mathrm{~nm}$ 
of ZTO was selected as the optimal thickness. (d) $J-V$ scans comparing a reference opaque device with evaporated heterojunction $n$-type contacts, the best device without ZTO showing poor $F F$, and the improved FF with ZTO (N14). (e) EQE and 1-R of the semi-transparent device in Supplementary Figure 2d with illumination through the glass side. Note, Figure 1 in the main text shows $J-V$ and EQE taken through the $\mathrm{SnO}^{2} / \mathrm{ZTO}$ bilayer side, as this is what is most relevant to the monolithic tandem performance. (f) Continuous maximum power tracking of opaque and semi-transparent devices from Supplementary Figure 3d.

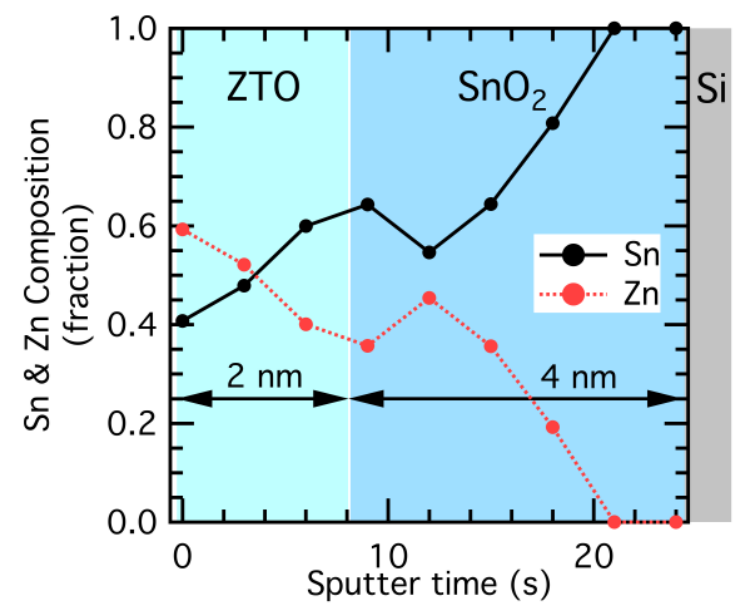

Supplementary Figure 4. X-ray photoelectron spectroscopy sputter depth profile showing how the $\mathrm{Zn}$ concentration drops off quickly at the $\mathrm{ZTO} / \mathrm{SnO}_{2} \mathrm{ALD}$ interface.

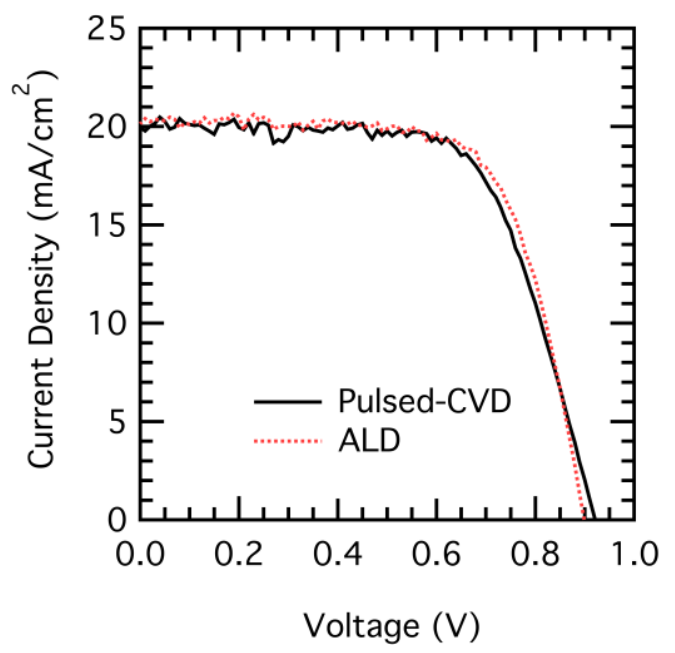

Supplementary Figure 5. Comparison of the J-V curves for single-junction perovskite devices with ALD vs. pulsed-CVD electron contacts. 

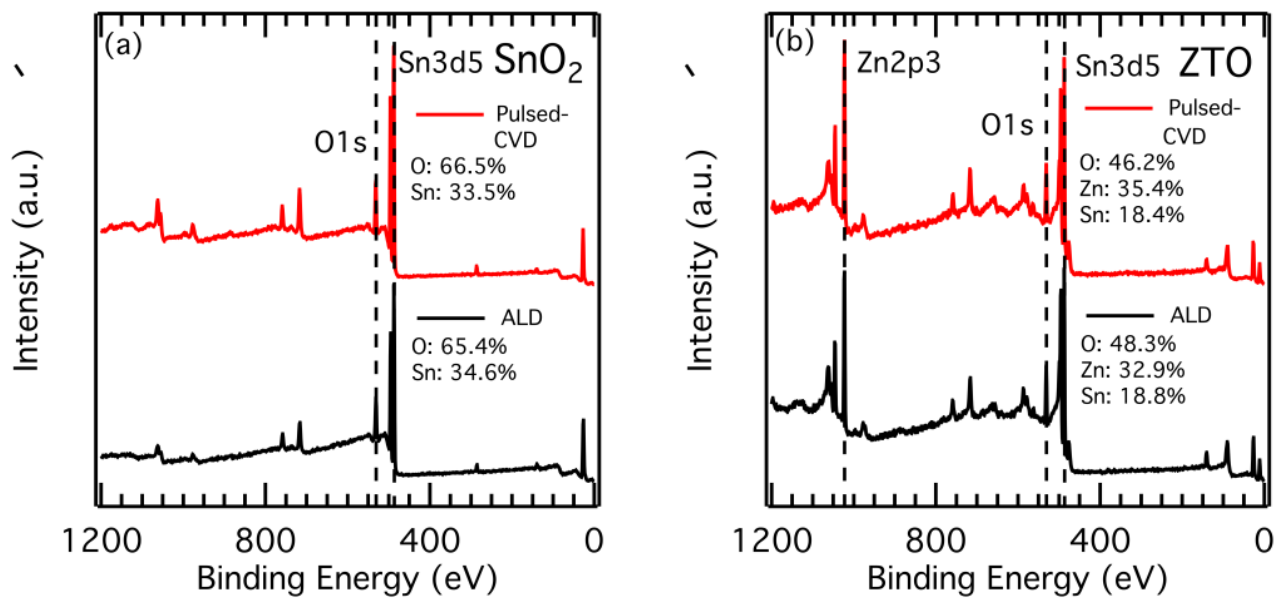

Supplementary Figure 6. XPS elemental composition data comparing the (a) $\mathrm{SnO}_{2}$ and (b) ZTO layers deposited through ALD and pulsed-CVD processes. 
(a) Absorption and Losses (100 nm ITO)

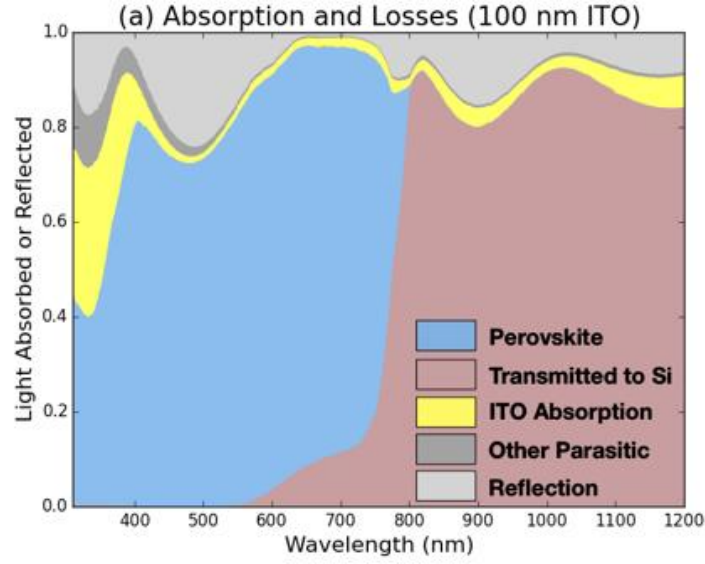

(c) Absorption and Losses (200 nm ITO)

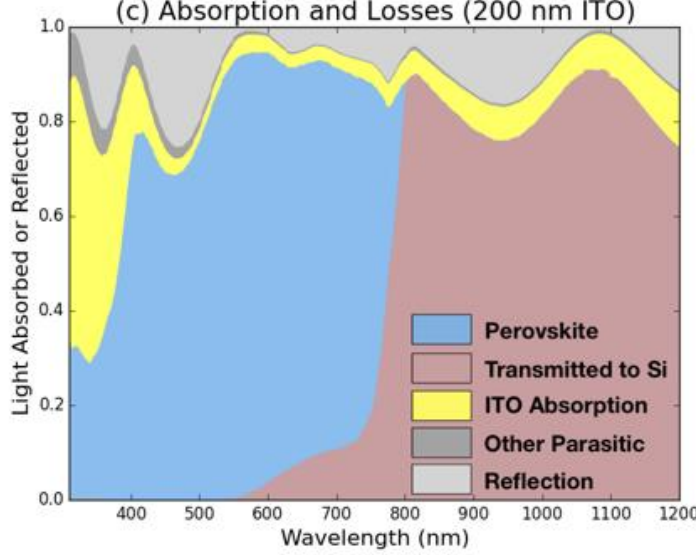

(e) Absorption and Losses (400 nm ITO)

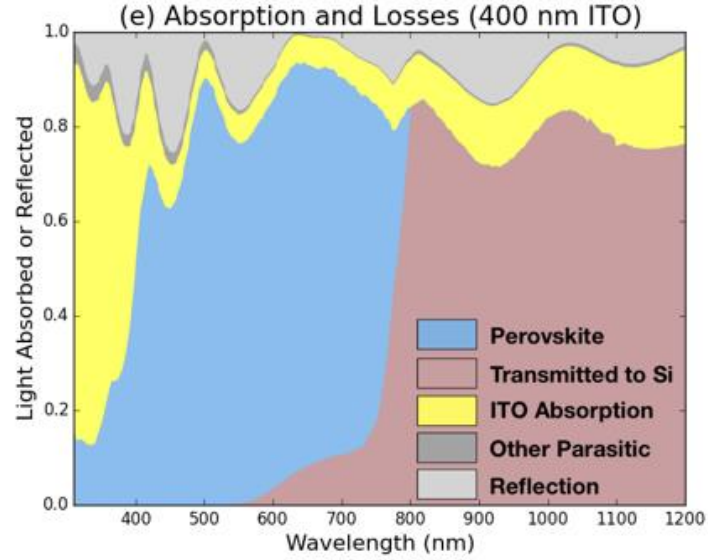

(b) Absorption and Losses (150 nm ITO)

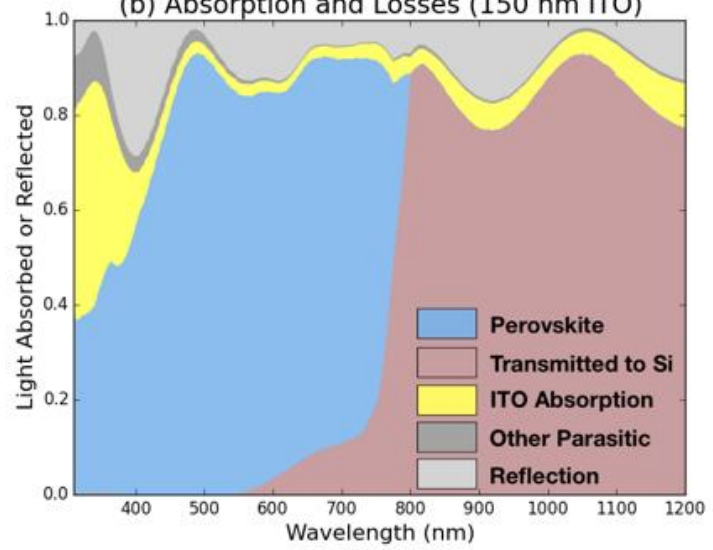

(d) Absorption and Losses (300 nm ITO)

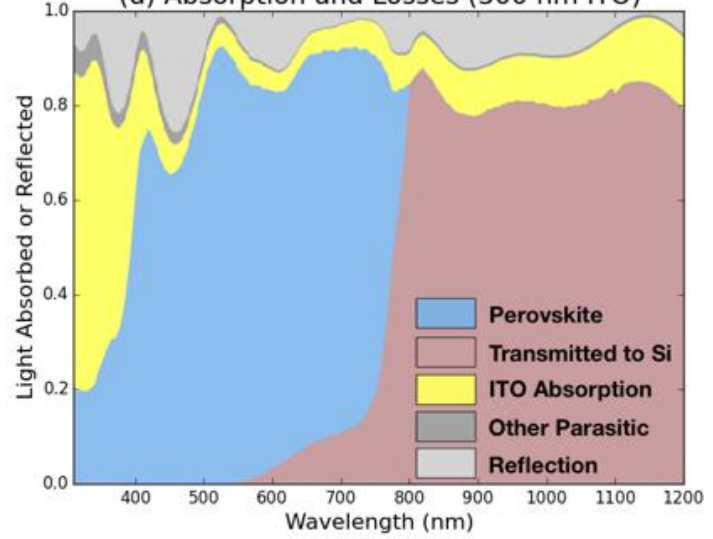

(f) Currents Absorbed or Lost

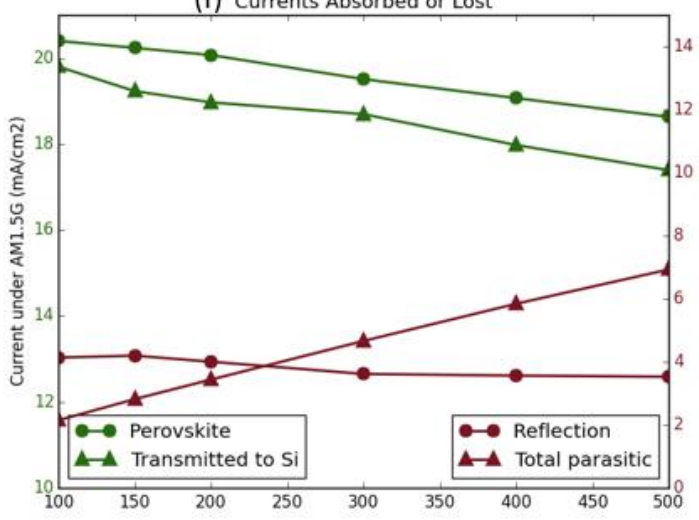

Supplementary Figure 7. Optical simulations of the tandem device stack were performed using a onedimensional transfer matrix formalism ${ }^{1}$ implemented in home-built code described previously ${ }^{2}$. Currents corresponding to light reflected, transmitted, or absorbed were computed by integrating over the AM1.5G spectrum. Simulations were performed for a range of top ITO thicknesses of (a) 100nm, (b) 150 $\mathrm{nm}$, (c) $200 \mathrm{~nm}$, (d) $300 \mathrm{~nm}$, and (e) $400 \mathrm{~nm}$. (f) shows the total integrated current absorbed in the perovskite or lost to parasitic absorption. Differences between theoretical and experimental reflections can be attributed to thickness variation in our perovskite sample and surface roughness, which will dampen the interference fringes in the measured reflectance. 


\section{Stanford}

page 9

\section{Perovskite/HIT tandem Cell}

Device ID: HIT4

2:16 PM 8/9/2016

Spectrum: ASTM G173 global
Device temperature: $25.0 \pm 1.0^{\circ} \mathrm{C}$

Device area: $0.990 \mathrm{~cm}^{2} \pm 0.1 \%$

Irradiance: $1000.0 \mathrm{~W} / \mathrm{m}^{2}$

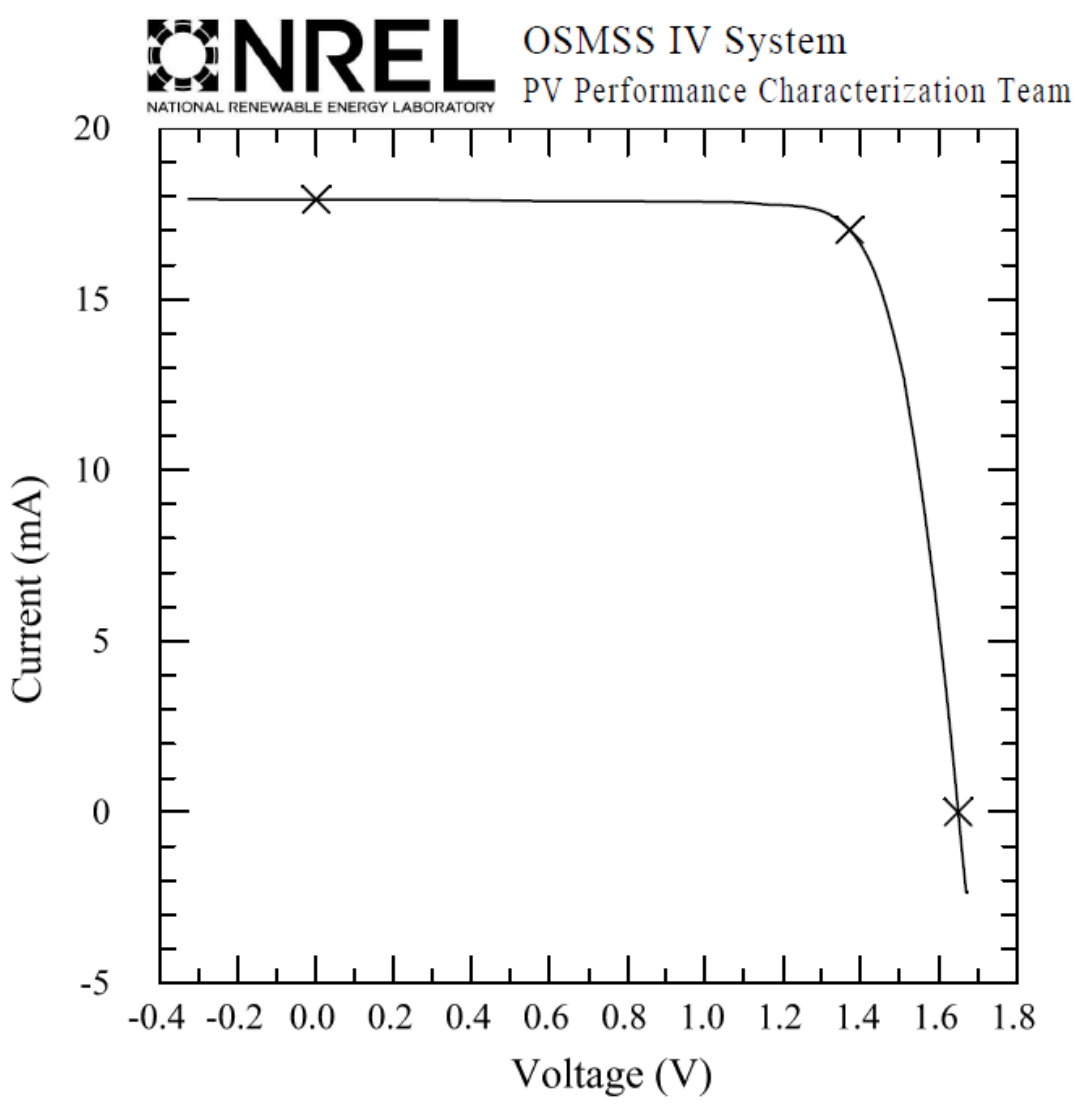

$\mathrm{V}_{\mathrm{oc}}=1.6506 \mathrm{~V} \pm 0.6 \%$

$\mathrm{I}_{\max }=17.023 \mathrm{~mA} \pm 1.3 \%$

$\mathrm{I}_{\mathrm{sc}}=17.910 \mathrm{~mA} \pm 1.3 \%$

$\mathrm{V}_{\max }=1.3712 \mathrm{~V} \pm 0.6 \%$

$\mathrm{J}_{\mathrm{sc}}=18.093 \mathrm{~mA} / \mathrm{cm}^{2} \pm 1.3 \%$

$\mathrm{P}_{\max }=23.342 \mathrm{~mW} \pm 1.4 \%$

Fill Factor $=79.0 \% \pm 0.3 \%$

Efficiency $=23.58 \% \pm 1.4 \%$

10.0 seconds per data point

Supplementary Figure 8. NREL certification of 23.6\%-efficient perovskite/silicon tandem device. 

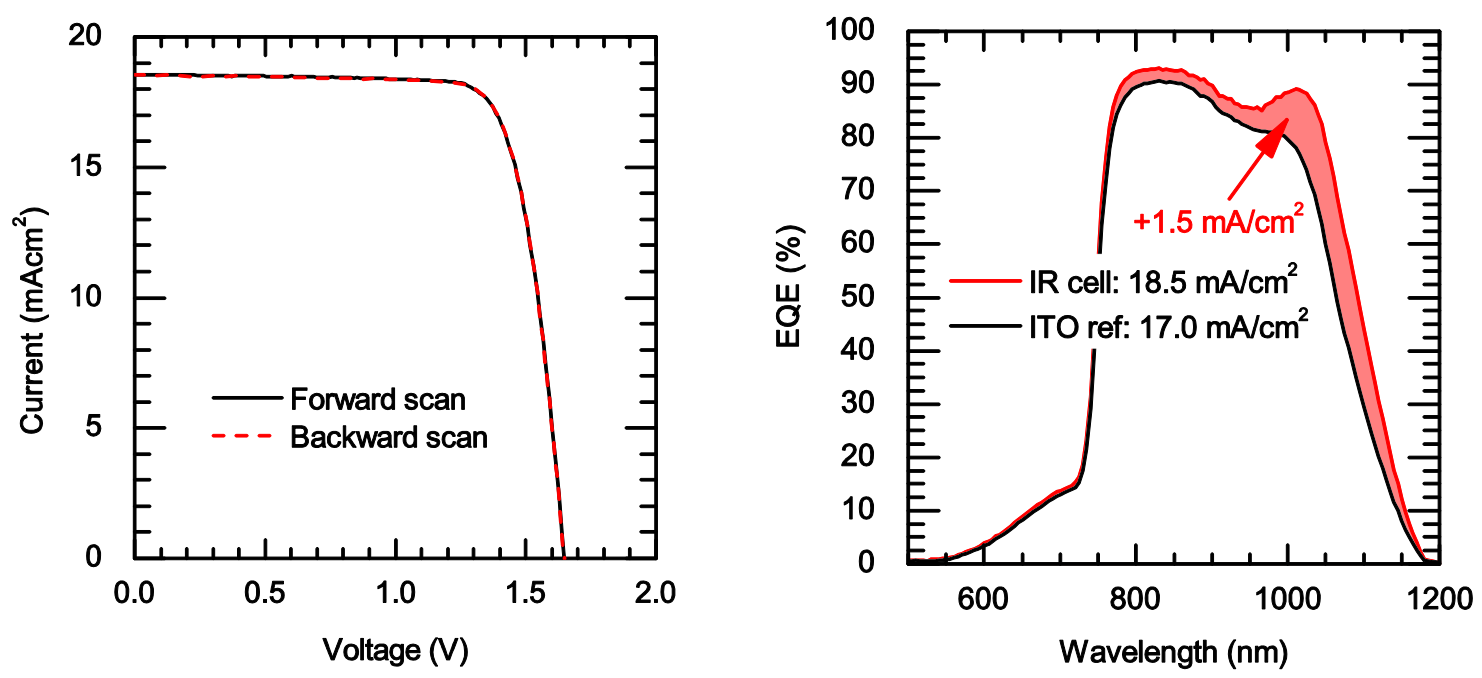

Supplementary Figure 9. (a) J-V scans of the perovskite/silicon tandem device sweeping forward (negative-to-positive bias) and backward (positive-to-negative bias) showing negligable hysteresis. (b) EQE of silicon bottom cells with and without SiNP rear reflectors, showing a $1.5 \mathrm{~mA} / \mathrm{cm}^{2}$ increase in $J_{\text {sC }}$ in the IR-tuned cell.
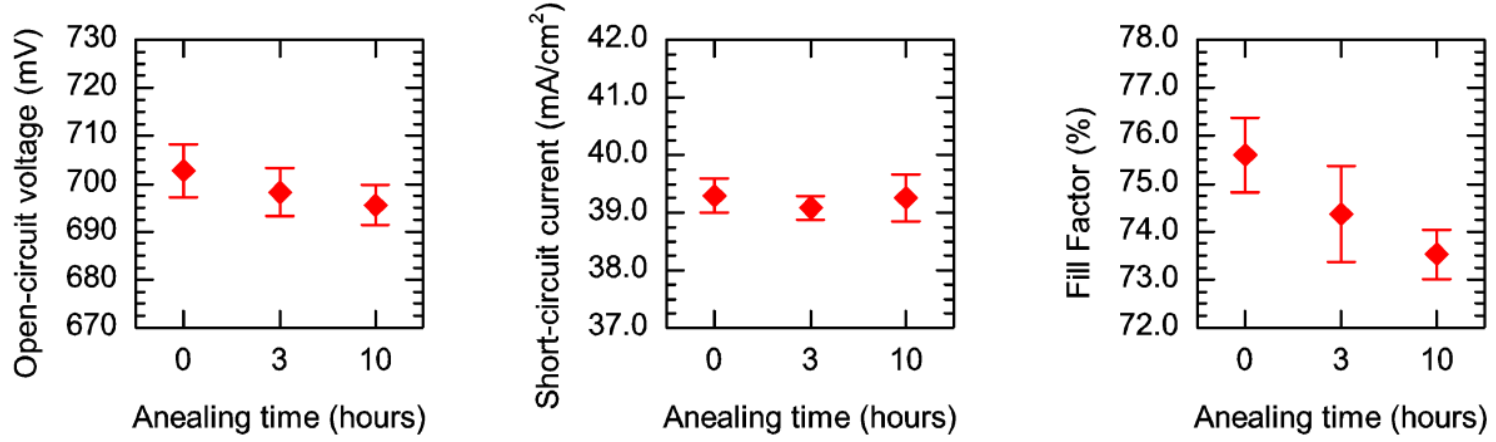

Supplementary Figure 10. In order to determine the annealing temperature window for our solutionprocessed $\mathrm{NiO}_{x}$ layer, we tested the thermal stability of silicon heterojunction solar cells. The devices were ramped to $190{ }^{\circ} \mathrm{C}$ in 30 minutes, held at $190{ }^{\circ} \mathrm{C}$ for $3-10$ hours, and then ramped down to room temperature over 30 minutes. We observed a nearly $3 \%$ relative drop in the $F F$ of the silicon solar cells after thermal stressing, but minimal degradation of the $V_{\mathrm{Oc}}$ and $J_{\mathrm{sc}}$. We conclude from this experiment that the $\mathrm{NiO}_{x}$ can be processed at $190{ }^{\circ} \mathrm{C}$ on top of the silicon heterojunction cells with minimal concern for a-Si:H degradation. The error bars designate the standard deviation of the measured results with a sample size of 3 . 

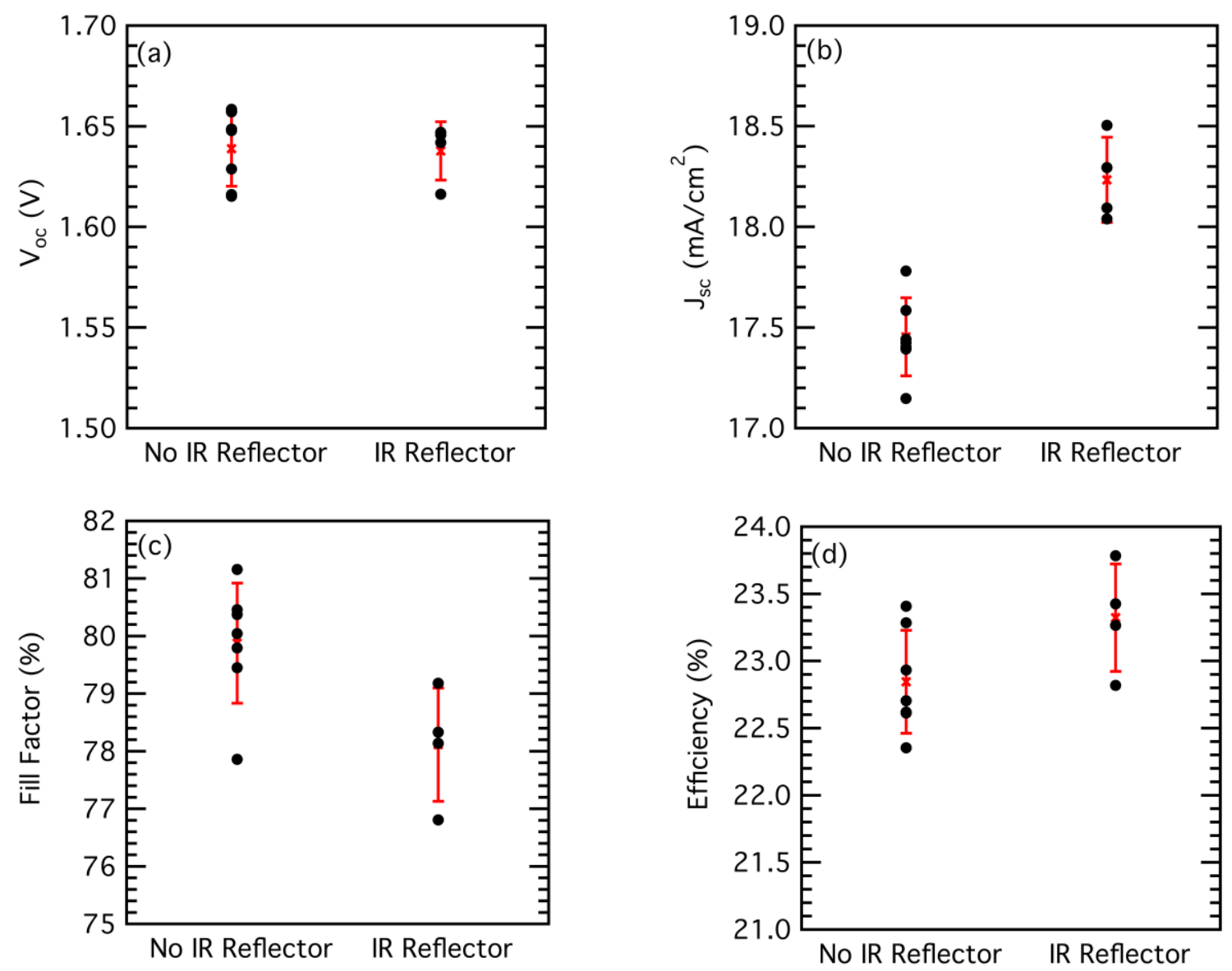

Supplementary Figure 11. Performance of the full batch of 12 of perovskite/silicon tandem solar cells ( 4 with IR reflectors and 8 with no IR reflector) that yielded the record device. The batch included silicon bottom cells with and without SiNP IR rear reflectors; these are compared. Individual device performances (black dots) as well as batch average (red cross) and standard deviation are shown (red lines).

\section{Supplementary References}

1. Pettersson, L. A. A., Roman, L. S. \& Inganas, O. Modeling photocurrent action spectra of photovoltaic devices based on organic thin films. J. Appl. Phys. 86, 487-496 (1999).

2. Burkhard, G. F., Hoke, E. T. \& McGehee, M. D. Accounting for interference, scattering, and electrode absorption to make accurate internal quantum efficiency measurements in organic and other thin solar cells. Adv. Mater. 22, 3293-3297 (2010). 